\title{
Interest Rate Clustering in UK Financial Services Markets
}

by

\author{
John K. Ashton \\ Policy, University of East Anglia \\ and \\ Robert Hudson \\ Leeds University Business School
}

Norwich Business School and the ESRC Centre for Competition

\section{CCP Working Paper 06-14}

\begin{abstract}
In applications as diverse as banking, supermarket and catalogue sales, it has been clearly identified that prices have a strong propensity to cluster around certain digits. This study forwards an explanation and empirical investigation of price clustering in retail markets, through an examination of how interest rates cluster in two UK financial services markets. It is proposed that price or interest rate clustering forms in retail markets as firms wish to maximise returns from customers who have difficulties in recalling and processing price information. To compensate for limited recall, individuals use different behavioural strategies, such as rounding and truncating number information, which are recognised by firms when setting prices or interest rates. This theory is developed and tested using a dataset of retail interest rates from the UK which enables interest rate clustering to be viewed in both lending and investment markets, and at different levels of financial involvement. It is found that interest rate clustering occurs in a manner consistent with firms maximising returns from customers who have less ability in recalling and processing number information. Further, the degree of interest rate clustering observed is exaggerated for investors of smaller monetary quantities, for firms which profit maximise and at higher market rates of interest.
\end{abstract}

October 2006 
JEL Classification Codes: E43; G21

Keywords: Interest Rate Setting, Mortgages, Deposits, Limited Recall

\section{Acknowledgements:}

We would like to thank Moneyfacts PLC for the use of their extensive data set on UK financial services. Further we would like to thank Yenner Altunbas, Steve Davies and the participants of the Wolpertinger Conference at the University of Valladolid 2006, and a ESRC Centre for Competition Policy seminar held at the University of East Anglia, for their helpful comments. The support of the Economic and Social Research Council is also gratefully acknowledged. The usual disclaimer applies.

\section{Contact Details:}

John K. Ashton, Norwich Business School and the ESRC Centre for Competition Policy, University of East Anglia, Norwich, NR4 7TJ; t: 01603 591178; f: 01603 593343; e: j.ashton@uea.ac.uk

Robert Hudson, Leeds University Business School, Leeds, LS2 9JT; t: 0113343 1677; e: rsh@lubs.leeds.ac.uk 


\section{Introduction}

Previous empirical evidence has identified clustering of prices around certain digits as a common feature in product and financial markets. This paper extends this literature observing and explaining the phenomenon through the examination of clustering among UK retail financial services interest rates. In this study, price or interest rate clustering is viewed to emerge as an outcome of firms' profitmaximising. It is assumed that interest rates are set in a clustered manner to maximise returns from customers who employ rounding and truncation strategies to accommodate limited number recall.

This examination of retail interest rate setting differs from previous empirical work examining the topic. It has been common to assume that retail interest rates set by banks are subject to structural factors such as the costs of wholesale funds (Heffernan 1997), market structure (see Berger and Hannan 1989, Diabold and Sharpe, 1990, Heffernan 2002, Jackson 1997, and Neumark and Sharpe 1992), the ownership form of banks (Ashton and Letza 2003) or the degree of market competition (Hannan and Liang 1993). This study extends this understanding of interest rate setting by both identifying the extent of interest rate clustering in UK retail banking markets and advocating a distinct behavioural model of limited consumer recall to account for interest rate clustering.

This assessment is timely as the influence of limited consumer recall on retail interest rate clustering has already been identified in US banking markets (Kahn et al 1999). As recent evidence has indicated that a substantial proportion of UK consumers make poor financial decisions, undertake little comparison of products, are often reluctant to switch products, and rely heavily on product information issued by financial services suppliers (FSA 2006), it is deemed pertinent to examine whether limited recall is also an influence in the UK. Further, responding to consumer protection concerns, UK financial regulators, including the Financial Services Authority (hereafter FSA) and the Office of Fair Trading (hereafter OFT), have examined the forms of advertising and clarity of 
information provided on a wide range of financial services products (OFT 1997, 1999), making this assessment pertinent to a wider policy discussion.

In this study we develop an explanation grounded in limited recall of number information as to how price clustering forms in retail markets. This addition to the price clustering and the related marketing literatures on reference pricing advances the wider literature on this topic, as a cohesive framework which examines the mechanisms and antecedents of price clustering has yet to be developed (Mazumdar et al 2005). Indeed only relatively few studies have developed a theoretical explanation of the behavioural causes of price clustering in retail markets (e.g. Basu 2006, Kahn et al 1999). The study by Kahn et al (1999) provided a theoretical explanation of interest rate clustering as a phenomenon which arises as banks maximise revenue from customers with limited recall who truncate number information. This theory was empirically examined using data from US deposit markets indicating very strong elements of interest rate clustering around fractions and the digits 0 and 5 . Further, the study by Kahn et al (1999) reported that both the 'limited recall' of customers and the market structure of the banking market had a significant association with the degree of clustering.

This study extends the work of Kahn et al (1999) in four respects. Initially, we examine truncation, as undertaken by Kahn et al (1999), and extend this contribution through considering rounding, and the use of rounding and truncation in combination, as number processing strategies used by customers with limited recall. It is posited that interest rate setters are aware some customers use these behavioural strategies, and consequently set interest rates to maximise returns from these customers, which results in interest rate clustering. Secondly, by empirically examining both deposit and mortgage markets, where interest rates denote benefits and costs to customers respectively, the consistency of our model predictions may be examined. This develops the contribution of Kahn et al (1999) through both assessment of 
clustering in a distinct national market and observation of clustering in mortgage markets in addition to deposits, which were considered by Kahn et al (1999). Lastly, we examine the incidence of interest rate clustering behaviour which occurs in savings products supplied to investors of different monetary quantities. This development of the work by Kahn et al (1999) allows an assessment of the consistency of these behaviours across different levels of financial involvement. To achieve these goals the paper is divided into five sections. After this introduction, the diverse literature considering the antecedents of clustering in price setting will be examined. This review of the causes of clustering will then be developed to model the influence of limited recall on interest rate clustering, in section three. Section four will provide both a description of the data set and will test the key insights of the model. Lastly, conclusions, the wider policy implications of this work and suggestions for future research will be made in section five.

\section{Why Does Price or Interest Rate Clustering Occur?}

The pricing of different commodities, goods and services, and the incidence of clustering around certain digits has been examined by many different academic traditions, including consumer research, finance, economics, marketing and statistics. This reflects the long recorded human tendency to associate with rounded numbers, halves, quarters and even numbers (e.g. Yule 1927). Indubitably, price clustering has been observed in many financial markets trading in equity (e.g. Bessembinder 1997, Christie and Schultz 1994, Christie et al 1994, Chung et al 2004, Cooney et al 2003, Niedferhoffer, 1966; see Michell 2001, for a review), gilts (Ap Gwilym et al 2005), options (Ap Gwilym et al 1998, Ap Gwilym and Alibo 2003), IPOs (Kandel et al 2001), foreign exchange (Sopranzetti and Datar 2002), real estate markets (Palmon et al 2004), asset markets (Grossman et al 1997), the setting of tax rates (Ashworth et al 2003), and even the reporting of financial accounts (Das and Zhang 2003). While the 
literature on equity pricing does not provide a direct explanation for clustering in retail banking markets, it does, as an intensively researched area, provide many general insights as to why clustering can emerge in markets. This literature documenting why price setters have a preference for certain digits may be delineated into contending perspectives which emphasise the industry or environmental influences and the behavioural strategies for accommodating limited number recall. These distinct approaches to explaining why clustering may arise will be elaborated in turn.

An extensive literature seeks to explain the clustering of prices and price setting behaviour, of financial firms in terms of environmental or industry factors. Within this literature, the relationship of the individual firm to the environment in which the firm operates is viewed to have a strong influence on how interest rates are established. In much of the literature on price clustering in financial securities, this phenomenon is associated with a range of environmental factors, including the industrial structure of individual markets (Grossman et al 1997), the depth of markets (Ahn et al 2005), cultural factors (Brown et al 2002), the time of day a trade is undertaken (Ohta 2006), and collusion (Christie and Schultz 1994, Christie et al 1994). Indeed differences in the structure of markets, such as the adoption of dealer or auction markets, have been observed to be a highly significant determinant of price clustering (Huang and Stoll 2001). Within all of these structural explanations, the setting of clustered prices is viewed to be a phenomenon that is driven by forces outside the control of the price setters.

The behavioural explanations as to why certain digits are more salient than others centre around the mechanisms through which individuals both recall and process number information. Central to these explanations of number processing is the perception of the brain being a tool of prediction and estimation rather than a calculation device (Kopcke et al 2004). This has led to the use of number processing strategies to reduce time and effort when comprehending pricing as a rational act for individuals who choose to spend less time with such decisions 
(Basu 2006). Indeed in assessing number recall and prediction, Dehaene and Mehler (1992) report that "adults show remarkably stable and reproducible effects in some simple number-processing tasks", with certain number processing and estimation techniques used widely across many cultures. Within these explanations, the form and comprehension of the measurement scale are critical; for example, on a decimal scale, the numbers 0 and 5 are easier to recall. These insights are supported by empirical work examining different trading scales in equity (Chung et al 2003), and option markets (Ap Gwilym et al 2005) which lead to different forms of price clustering.

This behavioural literature indicates that the ease with which a number is retrieved or recalled from memory - termed its accessibility or availability - varies according to the number being considered. Influences which make recall of numbers or the 'sphere of haziness' more and less problematic include the distance between numbers (Thomas and Morwitz 2005), the size of numbers (Dehaene 2001) and the frequency of numbers (Ashcraft, 1992). These effects are developed during the conversion of numerical data into a single mental magnitude placed on an internal scale, even before all digits have been read (Thomas and Morwitz 2005).

To overcome these cognitive limitations in number recall, mental estimation techniques or strategies are used by individuals to assist in the comprehension of numbers. Two commonly advocated strategies for assisting comprehension and processing of number are truncation and rounding. Truncation as an encoding strategy involves cutting off digits on the right, to leave the most important digits on the left. i.e. 199 could be truncated to 190 or to 100 . Rounding is an encoding strategy which attends sequentially to each digit of the price considered. If the number is not already a round number an individual would round a number to the closest reference number, where the degree of rounding depends on the linear proximity to a reference number (Brown et al 2002). 
These features of limited number recall, processing and manipulation, appreciated by some customers, may alternatively be viewed as an attribute to be exploited by price setters. Prospect theory and framing explanations (Tversky and Kahnman 1986, Kahnman and Tversky 1979) indicate consumers are generally risk averse for gains and risk seeking for losses. This leads to perceived gain and underestimation effects, as individuals make choices based in terms of relative gains or losses from an initial reference point and not the absolute states. Further, these problems of information use and interpretation are often compounded as individuals have difficulties in assigning accurate gains and losses to outcomes due to limited recall.

These insights help explain price clustering as perceived gain effects indicating that a high incidence of 9 s occurs as 0 is a decimal reference point, i.e. a customer would round the number 9 up to 0 , leading to a perceived small gain. Consequently prospect theory indicates that certain numbers, such as 9 and 4 , would be over-represented in prices. Schindler and Wiman (1989) suggest such mechanisms are widely used in pricing decisions by firms. Indeed price setting using $9 \mathrm{~s}$ is commonly employed to forward an impression of low prices for relatively high priced market offerings (Anderson and Simester 2003, Schindler 2001).

Further, the difficulties individuals face in processing numbers may be complicated by the nature of interest rates - the focus of this work. Retail financial services quote interest rate yields rather than individual prices for many financial services. Interpretation of the value yields produce demands not only the recognition of prices, yet also calculations as to the 'value' of these yields. It is expected that the problem of limited recall would be compounded in retail financial markets as difficulties appreciated by individuals in comprehending monetary yields have long been acknowledged (e.g. Shafir et al 1997). Indeed, experimental evidence indicates that when estimating the monetary consequences of a straightforward and familiar act many individuals have 
difficulties in being precise about valuations (Butler and Loomes 1988). Early theoretical contributions (e.g. Grossman and Stiglitz 1980) have also proposed that as the costs of recalling and processing information rise, a higher proportion of customers will be poorly informed.

The utility of these insights as to how customers view, process and assess price information has driven much of extensive literature identifying or advocating the use of price clustering in marketing. This literature indicates that price clustering has not only been a significant influence on demand for individual products (Wedel and Leeflang 1998), but also alters the quality perception of the product (Striving 2000), and aids the profitability of firms offering products using psychological or behavioural prices (Bizer and Schindler 2005).

To summarise, the issue of price clustering has been recognised in a range of different markets and a diversity of factors are advocated by way of explanation. A consistent theme within these explanations is the motivation of price setters. Within environmental explanations, price clustering is a phenomenon caused by exogenous factors. Behavioural explanations view price clustering as a benign activity which assists customers in decision making, as a useful tool to assist firms' pricing decisions and as an action undertaken by price setters to maximise return from consumers with less ability to recall and process number information. From this review a model is developed which emphasises a behavioural interpretation of price clustering, where interest rates are set to maximise returns from customers. This model demonstrates how firms maximise profits from customers with limited number recall, using rounding and truncation as antecedents of clustering behaviour in retail interest rates. 


\section{Models of Deposit and Mortgage Pricing with Limited Recall Customers}

In this section a model of a bank's optimal interest rate setting for deposit and mortgage products when limited recall exists amongst customers is proposed. Two strategies for accommodating limited recall, the truncation and rounding of numbers, are used to explain how clustering forms in both deposit and mortgage markets. The model is developed over 6 cases: for truncating investors, rounding investors, truncating and rounding investors, for truncating borrowers, rounding borrowers, and lastly for truncating and rounding borrowers. The amount of truncation and rounding in all cases will vary between customers.

Following a long tradition of research (Salop and Stiglitz 1977, Kahn et al 1999) we consider two types of customer. Firstly, 'sophisticated' customers (investors and borrowers) who base decisions on posted interest rates ( $r_{d}$ for deposits and $r_{m}$ for mortgages), and secondly, 'naive' customers who employ number processing strategies before making decisions, are assumed. The number processing strategies of rounding and truncation are assumed to form an interest rate denoted $\left[r_{d}\right]^{r},\left[r_{d}\right]_{-}^{t}$ for deposits and $\left[r_{m}\right]^{r},\left[r_{m}\right]_{-}^{t}$ for mortgages. This framework provides continuity with the work by Kahn et al (1999). The model is specified initially for deposit investment and then for mortgage borrowing.

\subsection{Deposit Rates and Investment}

The analysis of deposit interest rates takes an alternative perspective to most work on price clustering. Deposit interest rates are effective prices which record benefits to consumers, as opposed to the costs of a transaction to consumers. For example, a rise in deposit interest rates is deemed to be beneficial and a fall is viewed negatively by consumers. Following Kahn et al (1999) the sophisticated depositor will have a desired holding of deposit products which would be represented by: 


$$
D=D\left(r, r_{d}, x\right)
$$

$r_{d}$ is the banks posted deposit rate, $r$ is the market rate and $x$ is a vector of other variables which influence demand for deposits. The demand of the naïve depositor who truncates interest rates will depend on:

$$
\mathrm{D}=\mathrm{D}\left(\mathrm{r},\left[\mathrm{r}_{\mathrm{d}}\right]_{-}^{\mathrm{t}}, \mathrm{x}\right)
$$

and extending the work of Kahn et al (1999), the demand of the naïve depositor who rounds interest rates will depend on:

$$
D=D\left(r,\left[r_{d}\right]^{r}, x\right)
$$

$\mathrm{k}_{\mathrm{T}}$ is the proportion of depositors who truncate interest rates, $\mathrm{k}_{\mathrm{R}}$ is the proportion of depositors who round interest rates and $\left(1-k_{R}-k_{T}\right)$ is the proportion of depositors who are sophisticated; $c$ represents non-interest expenses per $£$ of deposit and $r$ represents the wholesale funding rate (LIBOR) available to banks. The bank's profits may be presented as:

$$
\left(r-r_{d}-c\right)\left[\left(1-k_{T}-k_{R}\right) D\left(r, r_{d}, x\right)+k_{T} D\left(r,\left[r_{d}\right]_{-}^{t}, x\right)+k_{R} D\left(r,\left[r_{d}\right]^{r}, x\right)\right]
$$

If the bank only faced 'sophisticated' depositors (i.e. $\mathrm{k}_{\mathrm{T}}=0$ and $\mathrm{k}_{\mathrm{R}}=0$ ) and assuming that $\left(r-r_{d}-c\right) D\left(r, r_{d}, x\right)$ is a concave function of $r_{d}$, the bank's optimal profits can be computed. If $r_{d}{ }^{s}$ is the optimal deposit rate which maximises $\left(r-r_{d}\right.$ c) $D\left(r, r_{d}, x\right)$ this would be the optimal interest rate for a clientele of only sophisticated borrowers ${ }^{1}$. This model is developed for truncating and rounding investors and borrowers individually, and for investors and borrowers who both truncate and round.

\subsubsection{Case 1: Limited investor recall based on truncation}

Kahn et al (1999) analysed the case where there are only sophisticated investors and investors with limited recall based on truncation (i.e. the case where $k_{R}=0$ in

\footnotetext{
${ }^{1} \mathrm{r}_{\mathrm{d}}^{\mathrm{s}}$ is derived using calculus.
} 
equation (4)). If only some investors are sophisticated, the bank's profit function is discontinuous because the demand functions of naïve investors are not continuous. For example, a naïve investor who truncates to the integer component of a number will regard an interest rate change from $5.9 \%$ to $6.0 \%$ as a substantial increase from $5.0 \%$ to $6.0 \%$. This small change in the posted interest rate increases the perceived gains by naïve investors. Consequently, if a bank was faced only with naïve investors, it would maximise profits by always setting interest rates as the truncated part of the interest rate that would otherwise have been set. This position would attract the same demand from naïve investors, but requires lower interest payments by the bank. The amount of truncation used might well vary between customers. Some customers may truncate to the integer component of a number, others may truncate to a lesser degree, for example, to half, quarter or tenths of integers. Developing analytical models which allow for all possible degrees of truncation is needlessly complex. Instead we adopt an approach similar to Kahn et al and initially assume that all truncating investors truncate to the integer component of a number. This explains the existence of 'primary' pricing points at integer numbers. Straightforward generalisation of the model can then explain the existence of 'secondary' pricing points at even fractions of integers such as half, quarter and three-quarters of integers.

In general terms, the profit-maximising interest rate for a bank will depend on the proportion of investors who are naïve and sophisticated. Kahn et al (1999) analysed this situation to show that if $r_{d}{ }^{s}$ is the optimal interest rate when the bank was faced only with sophisticated investors, when some customers are naïve the bank's optimal deposit rate $r_{d}{ }^{*}$ lies within the closed interval $\left[\left[r_{d}{ }^{s}\right]_{-}^{t}\right.$, $\left.\left[r_{d}^{s}\right]_{+}^{t}\right]$. If the optimal interest rate is in the interior of this interval it can be determined by calculus to satisfy the first order condition:

$$
r-r_{d}{ }^{*}-c=\left[\left(1-k_{T}\right) D\left(r_{d}^{*}\right)+k_{T} D\left(\left[r_{d}^{*}\right]_{-}^{t}\right) /\left(1-k_{T}\right) \partial D\left(r_{d}^{*}\right) / \partial r_{d}^{*}\right.
$$


Overall, in the presence of naïve truncating investors, bank deposit rates will cluster at reference numbers, at the end points of this interval, which are integers in this case.

\subsubsection{Case 2: Limited investor recall based on rounding}

In this case, which is extended from Kahn et al (1999), we assume that there are only sophisticated investors and naïve investors with limited recall based on rounding (i.e. where $\mathrm{k}_{\mathrm{T}}=0$ in equation (4)). We additionally assume that investors round to the nearest integer or ${ }^{2}$. Again, if some investors are naïve the bank's profit function is discontinuous. For example, naïve investors will regard an interest rate change from $5.49 \%$ to $5.51 \%$ as a substantial increase from $5.0 \%$ to $6.0 \%$, given integer rounding. Thus a small interest rate change can substantially increase demand from naïve rounding investors and hence increase bank profits. If a bank is faced only with naïve rounding investors, profits are maximised by setting interest rates half way between two integers or reference points, assuming naïve investors round up numbers ending exactly half way between two integers. This position is advantageous for banks as it attracts the same demand as a higher interest rate but results in lower interest payments ${ }^{3}$.

The profit-maximising interest rate will depend on the proportions of investors that are naïve and sophisticated. We show in Appendix 1 that if $r_{d}{ }^{s}$ is the optimal interest rate if the bank was faced only with sophisticated investors then when some investors are naïve the bank's optimal deposit rate $r_{d}{ }^{*}$ lies within the closed interval $\left[\left[r_{d}^{s}\right]^{r}-0.5,\left[r_{d}^{s}\right]^{r}+0.5\right]$. There may be a point of discontinuity in this interval at the point $\left[r_{d}^{s}\right]^{r}-0.5+\delta$, where $\delta$ is the smallest interest rate increment recognised by the bank. This point of discontinuity reflects investors who will not round up at a number exactly half way between two integers, but will only round up if the rate is nearer to the integer above. If the optimal rate is in the interior of

\footnotetext{
${ }^{2}$ We acknowledge this approach can clearly be generalised to other degrees of rounding.

3 There is a potential complication in that it is not certain how naïve investors might round numbers ending exactly half way between integers (i.e. ending in 0.5). Some investors may not round up these numbers. In this event the bank may wish to set an interest rate slightly greater than half way between the integers so that an optimum number of these investors round up. For the purposes of the development of the analytical models in this section we assume that a rate increment equal to the smallest interest rate increment recognised by the bank will cause investors to round upwards.
} 
this interval, at a point where the function is continuous, it can be determined by calculus and it will satisfy the first order condition:

$$
r-r_{d}^{*}-c=\left[\left(1-k_{R}\right) D\left(r_{d}^{*}\right)+k_{R} D\left(\left[r_{d}^{*}\right]_{-}^{t}\right) /\left(1-k_{R}\right) \partial D\left(r_{d}^{*}\right) / \partial r_{d}^{*}\right.
$$

\subsubsection{Case 3: Limited investor recall based on truncation and rounding}

In the third case of sophisticated investors and investors with limited recall based on truncation and rounding (i.e. equation (4) applies), the profit-maximising interest rate will depend on the proportion of customers that are naïve and sophisticated. We show in Appendix 1 that if $r_{d}{ }^{s}$ would be the optimal interest rate if the bank was faced only with sophisticated depositors then the bank's optimal deposit rate $r_{d}{ }^{*}$ is in the closed interval:

$$
\left[\operatorname{MIN}\left(\left[r_{d}^{s}\right]_{-}^{t},\left(\left[r_{d}^{s}\right]^{r}-0.5\right)\right), \operatorname{MAX}\left(\left(\left[r_{d}^{s}\right]_{+}^{t}\right),\left[r_{d}^{s}\right]^{r}+0.5\right)\right]
$$

There may be profit discontinuities at a number of points within this interval including at the point $\left[r_{d}\right]^{r}-0.5+\delta$. If the optimal rate is in the interior of this interval, at a point where the function is continuous, it can be determined by calculus as outlined in Appendix 1.

\subsection{Mortgage Rates}

The assessment of mortgage interest rates differs from the assessment of deposits, as mortgage rates quantify a degree of costs to the consumer. This analysis is developed along similar lines to those observed for deposits and is summarised in Appendix 1.

\subsubsection{Case 4: Limited borrower recall based on truncation}

To analyse the case where only sophisticated borrowers and borrowers with limited recall based on truncation exist (i.e. the case where $k_{R}=0$ ), we again see that the bank's profit function is discontinuous, albeit at different points. We show in Appendix 1 that if $r_{m}{ }^{s}$ would be the optimal interest rate if the bank was faced 
only with sophisticated borrowers, then when some borrowers are naïve the bank's optimal mortgage rate $r_{m}{ }^{*}$ lies within the closed interval $\left[\left[r_{m}{ }^{s}\right]^{t}-\delta,\left[r_{m}{ }^{s}\right]^{t}+\right.$ - $\delta$ ], where $\delta$ is smallest interest rate increment recognised by the bank. If the optimal rate is in the interior of this interval it can be determined by calculus and it will satisfy the first order condition:

$$
r^{*}-r_{m}-c=-\left[\left(1-k_{T}\right) D\left(r_{m}^{*}\right)+k_{T} D\left(\left[r_{m}^{s}\right]_{-}\right)\right] /\left(1-k_{T}\right) \partial D\left(r_{m}^{*}\right) / \partial r_{m}^{*}
$$

\subsubsection{Case 5: Limited borrower recall based on rounding}

The fifth case examines sophisticated borrowers and borrowers with limited recall based on rounding (i.e. the case where $\mathrm{k}_{T}=0$ in equation [11]). We show in Appendix 1 that $r_{m}{ }^{s}$ is the optimal interest rate if the bank is faced only with sophisticated borrowers; but when the bank has naïve rounding customers, the bank's optimal mortgage rate $r_{m}{ }^{*}$ lies within the closed region $\left[\left[r_{m}{ }^{s}\right]^{r}-0.5,\left[r_{m}{ }^{s}\right]^{r}+\right.$ $0.5]^{4}$. If the optimal interest rate lies within the interior of this interval, at a point where the function is continuous, it can be determined by calculus and it will satisfy the first order condition:

$$
r^{*}-r-c=-\left[\left(1-k_{R}\right) D\left(r^{*}{ }_{m}\right)+k_{R} D\left(\left[r_{m}^{*}\right]^{r}\right)\right] /\left(1-k_{R}\right) \partial D\left(r^{*}\right) / \partial r^{*} m
$$

\subsubsection{Case 6: Limited recall based on Truncation and Rounding}

The last case considers sophisticated borrowers and borrowers who employ limited recall based on both truncation and rounding. In this case, the profitmaximising interest rate for a bank will depend on the proportion of borrowers that are naïve and sophisticated. We show in Appendix 1 that if $r_{m}{ }^{s}$ is the optimal interest rate if the bank is faced only with sophisticated borrowers, then when some borrowers are naïve the bank's optimal mortgage rate $r_{\mathrm{m}}{ }^{*}$ is in the closed interval:

$$
\left[\operatorname{MIN}\left(\left[r_{m}^{s}\right]^{t}-\delta,\left(\left[r_{m}^{s}\right]^{r}-0.5\right)\right), \operatorname{MAX}\left(\left[r_{m}^{s}\right]^{t}+-\delta,\left[r_{m}^{s}\right]^{r}+0.5\right)\right]
$$

\footnotetext{
${ }^{4}$ There may be a point of discontinuity in this interval at the point $\left[\mathrm{r}_{\mathrm{m}}\right]^{\mathrm{s}}+0.5-\delta$, where $\delta$ is the smallest interest rate increment recognised by the bank. This point of discontinuity reflects customers who will not round down at a number exactly half way between two integers.
} 
Again, there are profit discontinuities at a number of points within this interval including at the point $\left[r_{m}{ }^{s}\right]^{r}+0.5-\delta$. If the optimal rate is in the interior of this interval, at a point where the function is continuous, it can be determined by calculus as outlined in Appendix 1 and will satisfy the first order condition:

$$
\begin{aligned}
r_{m}{ }^{*}-r-c= & -\left[\left(1-k_{T}-k_{R}\right) D\left(r^{*}{ }_{m}\right)+k_{T} D\left(\left[r_{m}{ }^{*}\right]_{-}\right)+k_{R} D\left(\left[r_{m}{ }^{*}\right]^{r}\right)\right] \\
& /\left(1-k_{T}-k_{R}\right) \partial D\left(r_{m}^{*}\right) / \partial r_{m}^{*}{ }_{m}
\end{aligned}
$$

\subsection{Illustration of the Predictions}

These predictions of the theory can also be viewed graphically in Figures 1 and 2. These diagrams display the bank's profits as a function of the bank's deposit rate for 4 different proportions of naïve investors or borrowers (hereafter customers): a) all sophisticated customers, represented by the unbroken, smooth, concave curve; b) 25\% naïve customers; c) 50\% naïve customers; and d) $75 \%$ naïve customers. The axes of these diagrams indicate the bank profitability relative to the deposit or mortgage interest rates offered or charged by banks. Different proportions of naïve customers have distinct degrees of discontinuance in the profit line, as movements of the deposit rate around certain points has a major effect on the profitability of these investors. For example, moving from 0.059 to $0.060(5.9 \%$ to $6 \%)$ has a major positive effect on the profitability of the naïve truncating investors. Therefore if all the customers truncate rates naïvely, the bank's profits would increase from -0.13 to 1.82 given this interest rate movement for deposits. These profit discontinuities occur at integer points and this will lead to rates clustering at these points. For rounding customers, different interest rate points have a distinct effect on bank profitability due to different points of discontinuance. In the presence of naïve rounding customers these points of discontinuity occur at the mid-point between two integers, or at half points. The diagrams illustrate the influence of both rounding and truncation being employed together by naïve customers in deposit and mortgage interest rate setting respectively. Diagrams illustrating the influence of 
truncation and rounding separately on deposit and mortgage interest rate setting are displayed in Appendix 2.

These diagrams duplicate, for the case of deposit clustering, and extend calculations produced by Kahn et al (1999) and act as a point of comparison for the more general work on different types of investor considered. Specifically, Figure 1 shows how bank profits will vary with deposit rates for various combinations of naïve rounding and truncating and sophisticated investors. It can be seen, from Panel 3, that the presence of both types of naïve investors results in the clustering of bank deposit rates at both integers and half points. Figure 2 indicates interest rate setting, under conditions where borrowers both truncate and round numbers would result in a high incidence of observations just below integers and half points.

Figure 1: The banks profit and deposit rate for differing proportions of sophisticated and naïve truncating and naïve rounding investors

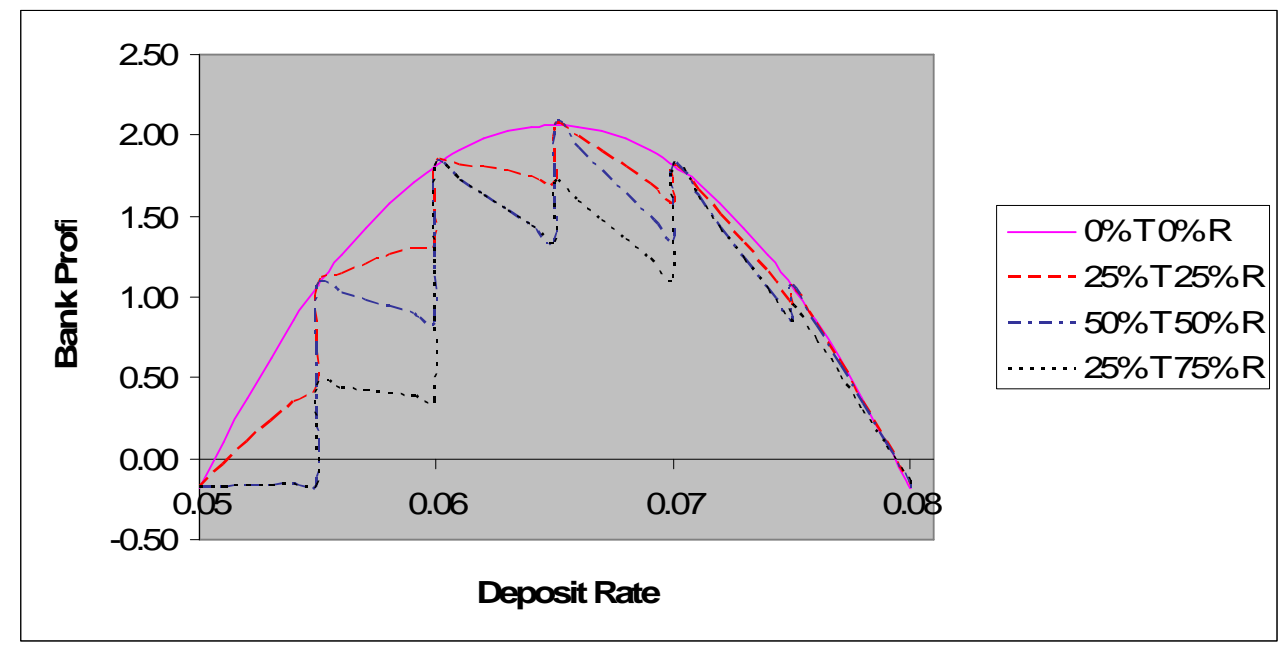


Figure 2: The bank's profit and mortgage rate for differing proportions of sophisticated and naïve truncating and naïve rounding borrowers

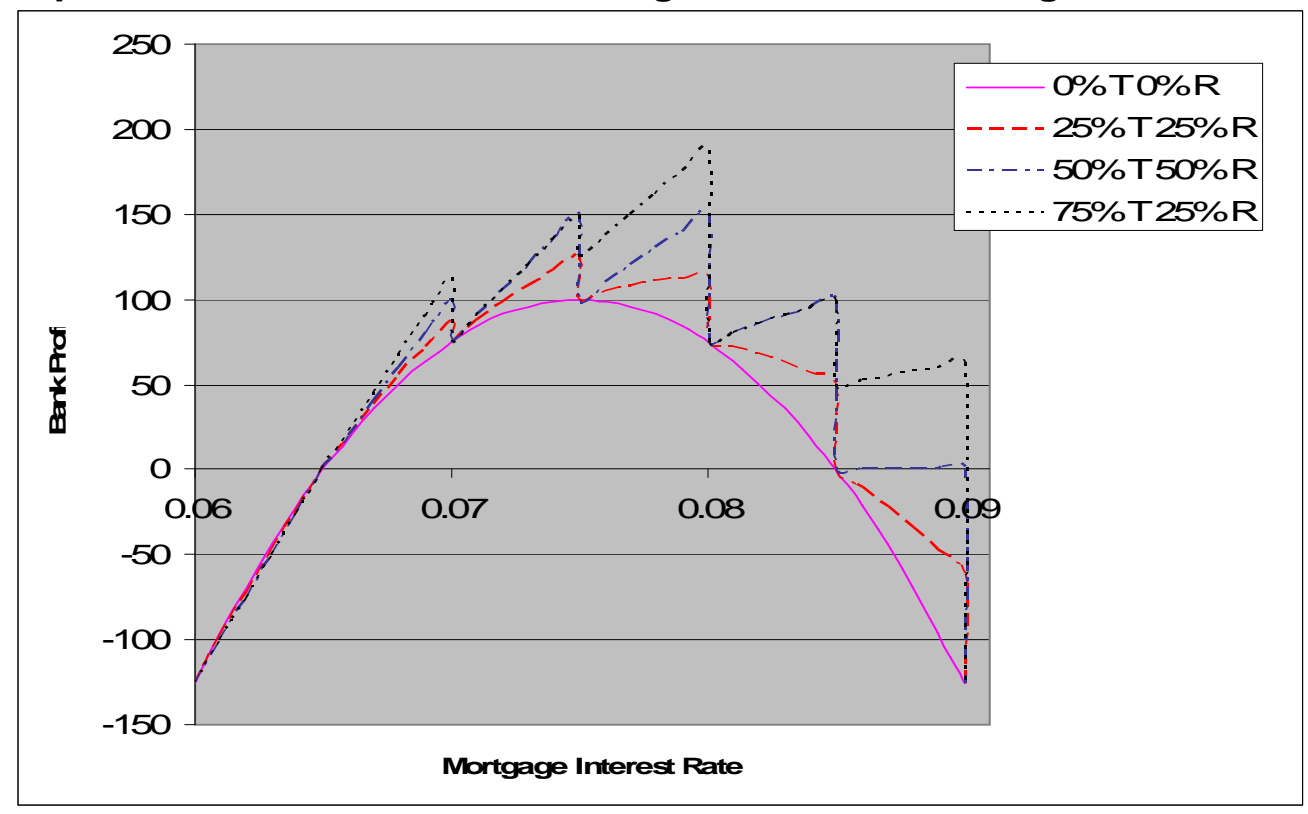

\subsection{Summary of Model Predictions}

The model provides a number of clear predictions of how interest rates are set in order to maximise profits from both naïve investors and borrowers. To maximise profits from naïve investors who truncate numbers, it would be expected that interest rates are clustered at integers. To maximise profits from naïve rounding investors, interest rates are set at the mid-point between integers or just above these points. Where both rounding and truncation are used by naïve investors, a high incidence of interest rate observations at integers and half points and just above half points is expected. For mortgages, naïve truncation would imply clustering just below integers. Naïve rounding would imply clustering just below half points or at half points. Where both rounding and truncation are used by naïve borrowers a high incidence of interest rate observations just below integers, just below half points and at half points are expected. Lastly, the degree of clustering is expected to be positively associated with the proportion of naïve customers who truncate and/or round interest rates. These predictions, derived from the model and the associated figures, are based on the assumption that truncation or rounding is done to whole integers. In reality many individuals may 
truncate or round in a more precise way. However, the models used in this section may easily be generalised to allow for this as outlined in section 4 , where we undertake an empirical assessment of whether interest rate clustering consistent with these predictions exists in the UK deposit and mortgage markets.

\section{Quantitative Analysis}

\subsection{Institutional Setting, Data, Descriptive Statistics and Key Predictions}

The UK banking market can be categorised as having the following features. The market is relatively concentrated with 517 banks and similar financial institutions resident in the UK in 2003 of which 236 were UK incorporated (IMF, 2003). Many of these institutions do not deal directly with the public and so are not relevant to this study. There are no legal restrictions preventing financial institutions from operating across the whole of the UK and indeed most do this although some of the smaller institutions market their products mainly to a regional customer base. Thus the market is not segmented by legislative or regulatory barriers and the institutions are generally in direct competition with one another. The market is regulated by the Financial Services Authority which is concerned with both prudential regulation and consumer protection. To date there has been no regulatory control of the interest rates that institutions charge.

As well as stock owned banks there is a substantial presence of mutual organisations, known as building societies, that have traditionally focused mainly on deposit taking and mortgage lending. In terms of products, it is common practice for deposit rates to depend on the amount in an account with better rates being given on larger savings. Mortgages are usual lent on a floating rate basis and, unlike deposits, the rate charged does not normally depend on the amount lent. 
Within the preceding section, testable predictions of interest rate clustering in deposit and mortgage markets are provided. These predictions are examined empirically using substantial data sets of interest rates for deposits and mortgages, provided by Moneyfacts PLC, a widely used data provider for the UK financial services industry. The data is also widely used in regulatory examinations of the UK financial services industry and provide a comprehensive survey of all market participants in both the UK deposit and mortgage markets. The data sets are contiguous - yet unbalanced due the entry and exit of both financial products and firms - to the deposit and mortgage markets (see Costanzo and Ashton 2006). The deposits data is provided for 1,294 deposit products issued by 186 firms, for 9 different deposit values ranging from $£ 1$ to $£ 100,000$. The mortgage data is the institution reference interest rate from which the interest charged on different mortgage contracts is assessed. This data is provided for 181 firms in total. The data is provided at monthly intervals over a 12 year period from 1993 to 2004, providing 446,770 observations for deposits and 15,414 observations for mortgages. The deposit data is pooled for all periods of notice and the presence of different product characteristics. While banking product characteristics influence the level of interest rate recorded (see Ashton and Letza 2003) they have not been previously associated with differences in the level and form of clustering (Kahn et al 1999). Descriptive statistics of this data are provided in Table 1.

The models developed in section 3 are based on the assumption that truncation or rounding is performed to whole integers. However, the models may easily be generalised to allow for more precise truncation or rounding. The predictions applying to integers, which can be regarded as primary pricing points, will also apply to secondary pricing points of 'even' numbers such as half, quarter and three-quarter integers and at five and ten basis points if individuals round with this precision. The predictions of the models to be tested in the analysis are listed below. 
Case 1) In the case of naïve truncating investors interest rate clustering will occur at pricing points.

Case 2) In the case of naïve rounding investors interest rate clustering will occur half way between points and at points just greater than half way between pricing points.

Case 3) In the case of naïve investors both rounding and truncating numbers, a higher incidence of observations at pricing points, half way between pricing points and at points just greater than half way between pricing points will occur.

Case 4) In the case of naïve truncating borrowers interest rate clustering will occur just below pricing points.

Case 5) In the case of naïve rounding investors interest rate clustering will occur just below points half way between pricing points and at points half way between pricing points.

Case 6) In the case of naïve borrowers both rounding and truncating numbers, a higher incidence of observations just below integers, just below points half way between pricing points and at points half way between pricing points.

It should be noted that a number half way between two integer pricing points might itself be a pricing point. 
Table 1: Descriptive statistics of interest rates for different quantities invested in deposit accounts and mortgages

\begin{tabular}{|c|c|c|c|c|c|}
\hline & $£ 1$ & $£ 500$ & $£ 1000$ & $£ 2500$ & $£ 5000$ \\
\hline Average rate & 2.14 & 2.82 & 3.07 & 3.36 & 3.68 \\
\hline Min & 0.05 & 0.05 & 0.05 & 0.05 & 0.05 \\
\hline Max & 9.00 & 9.00 & 9.00 & 9.10 & 9.25 \\
\hline Range & 8.95 & 8.95 & 8.95 & 9.05 & 9.20 \\
\hline St. dev & 1.71 & 1.61 & 1.62 & 1.63 & 1.60 \\
\hline Total obs. & 22917 & 33021 & 42479 & 51211 & 57127 \\
\hline Total banks & 158 & 167 & 174 & 179 & 183 \\
\hline & $£ 10000$ & $£ 25000$ & $£ 50000$ & $£ 100000$ & Mortgage \\
\hline Average rate & 4.05 & 4.28 & 4.46 & 4.57 & 7.0978 \\
\hline Min & 0.10 & 0.10 & 0.10 & 0.10 & 4.34 \\
\hline Max & 9.80 & 10.25 & 10.55 & 10.55 & 10.19 \\
\hline Range & 9.70 & 10.15 & 10.45 & 10.45 & 1.09022 \\
\hline St. dev & 1.62 & 1.63 & 1.65 & 1.66 & 5.85 \\
\hline Total obs. & 60706 & 60486 & 60238 & 58585 & 15414 \\
\hline Total banks & 185 & 186 & 185 & 183 & 179 \\
\hline
\end{tabular}

\subsection{Testing Framework}

The testing of these hypotheses is undertaken using four approaches. Initially, the distribution of interest rates or mantissas is represented graphically for both deposit and mortgage interest rates in Figures 3 and 4. The data informing these graphs is summarised in Appendix 3. Secondly, the distribution of recorded interest rates is identified and provided in Table 2. This assessment considers the presence of integers, half points, quarters, and other round numbers (e.g. 4.2, and 4.4) and the distribution of interest rate observations above and below these points, by 50 basis points, 25 basis points and 5 basis points. This assessment allows the predictions of the model, as to the location and distribution of interest observations to be examined, and allows comparison between mortgage interest rates, as well as comparison for interest rates for different quantities deposited. Further the use of other reference points including quarters and round numbers (e.g. $0.2,0.4,0.6$ etc.) enables the extent of the truncation or rounding of individuals to be ascertained. Third, we examine the 
location of interest rate clustering, to identify the degree and position of interest rate clustering for different quantities of deposit and mortgages. This assessment is undertaken through recording the numbers employed for $1^{\text {st }}$ (e.g. 5.12) and $2^{\text {nd }}$ (e.g. 5.12) decimal places for mortgages and interest rates for different quantities deposited. This is reported in Tables 3 and $4^{5}$.

Lastly, the influence of external factors on the degree of interest rate clustering is examined. The assessment of external influences on interest rate clustering considers the influence of market rates and the objective function of the firm setting interest rates. These factors are examined using probit regression models, specified as:

$$
r_{\text {cit }}=\alpha_{0}+\alpha_{1 t} A M R+\alpha_{2 t} S D M R+\alpha_{3 i t} \text { Mutual }+\varepsilon_{\text {it }}
$$

where $r_{\text {cit }}$ indicates whether a degree of clustering has occurred, at the following levels a) integer, and b) quarters or half points ${ }^{6}$, for $i$ firms and $t$ months. $\varepsilon_{\text {it }}$ denotes the error term and $\alpha_{0}$ the constant value. AMR and SDMR represent the average and dispersion of market rates measured by the mean and standard deviation of the 1 month LIBOR over the sample period, respectively. If higher average levels of market interest rate lead to greater retail interest rate clustering, a positive coefficient value $\left(\alpha_{1 t}\right)$ would be expected. Similarly if greater dispersion in market interest rates is associated more retail interest rate clustering a positive coefficient value $\left(\alpha_{2 t}\right)$ would be expected. The profitmaximising status of the firm is examined as the models presented in section three assume clustering is an outcome of firms maximising returns from customers. It is posited that firms which do not have to maximise returns, such as mutually owned savings banks, building societies or insurers, would not need to set interest rates in the clustered manner we predict. If profit-maximising firms set integer rates in a more clustered manner than mutually owned firms (MUTUAL),

\footnotetext{
${ }^{5}$ It is acknowledged that the presence of certain numbers at the second decimal place is influenced by the presence of certain digits at the first decimal place.

${ }^{6}$ Models were also run for round numbers $(0.2,0.4,0.6$ etc.) yet were found to be insignificant in all cases.
} 
a negative coefficient value $\left(\alpha_{3 i t}\right)$ would be expected as this variable is recorded as a dummy where 1 equates to mutual ownership and 0 to non-mutual ownership.

\subsection{The Distribution and Location of Interest Rate Clustering.}

The graphical representation of the distribution of interest rates is undertaken for a pooled population of interest rates for all sizes of deposit and for mortgage interest rates. This representation is presented over the 100 basis points, aggregated for all integer interest rates, or mantissa. From Figures 3 and 4, we can initially observe that the distribution of interest rate clustering differs substantially between deposit and mortgage interest rates. Secondly, the distribution of both deposit and mortgage interest rate observations indicate the degree of clustering is substantial.

For deposit interest rates, clustering occurs frequently at 5 basis point intervals. Within this distribution integers are the most frequently reported digits, with half points and quarters also recorded with a high frequency. Digits that are not multiples of 5 basis points are only reported with very low frequency. The high level of clustering at pricing points is consistent with some investors using naïve truncation (case 1), naïve rounding (case 2) and both these processes (case 3 ). In the presence of naïve rounding investors, one would also expect clustering above the mid points between pricing points and the evidence for this is outlined in section 4.4 .

The distribution of mortgage interest rates indicates clustering occurs at more points than is the case for deposits. In Figure 4, mortgage interest rate observations appear to cluster both at integers, half points and quarters and also immediately below these points by 1 and 5 basis points. The most frequently recorded points of clustering for mortgages, are just below integers, halves and quarters by 1 and 5 basis points. This pattern of observations is consistent with both naïve truncation and naïve rounding. 
Overall analysis of the mantissa of deposit and mortgage interest rates gives very strong evidence that rates cluster in accordance with banks seeking to maximise profits given the existence of naïve customers. This clustering occurs in a manner where both rounding and truncation processes are used at a number of levels of precision.

\section{Figure 3: Mantissa for Deposit Rates}

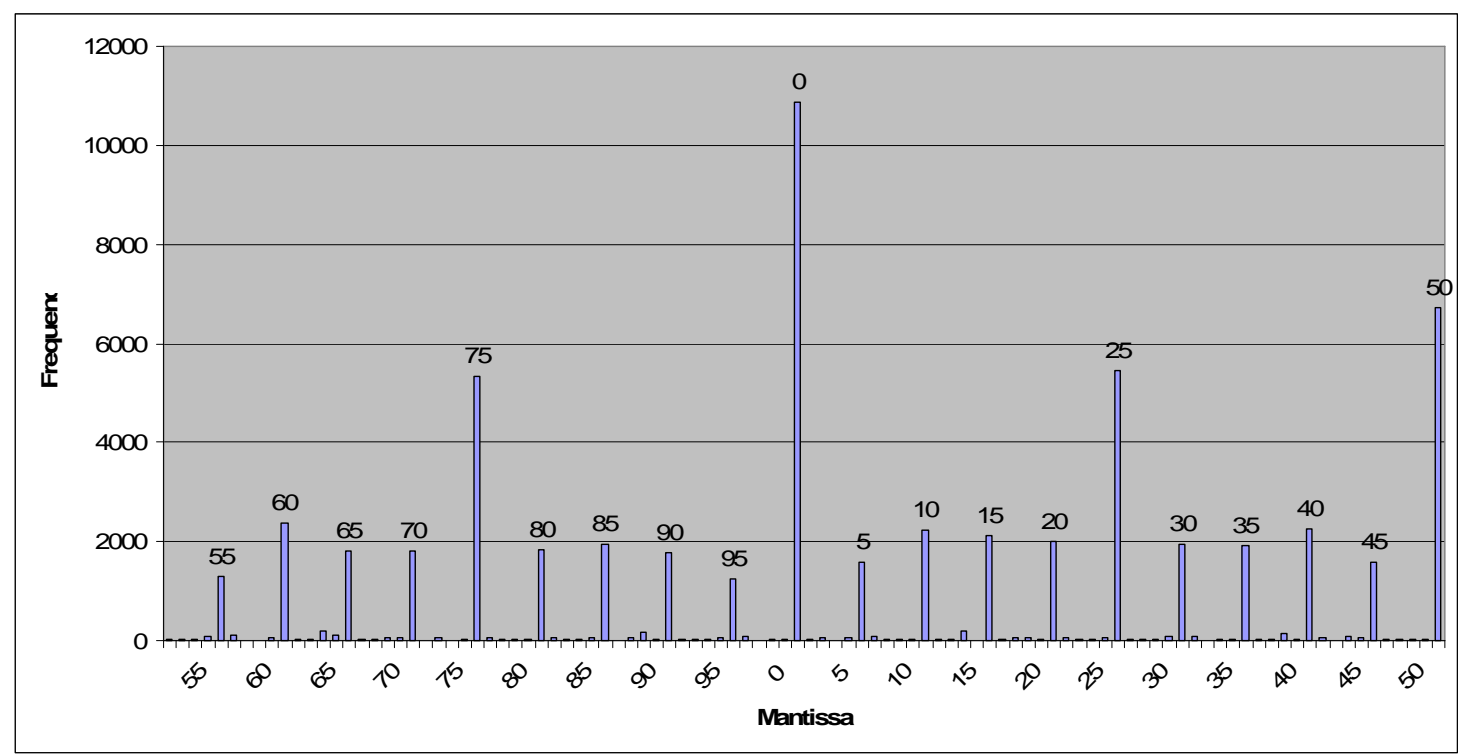

Figure 4: Mantissa for Mortgage Rates

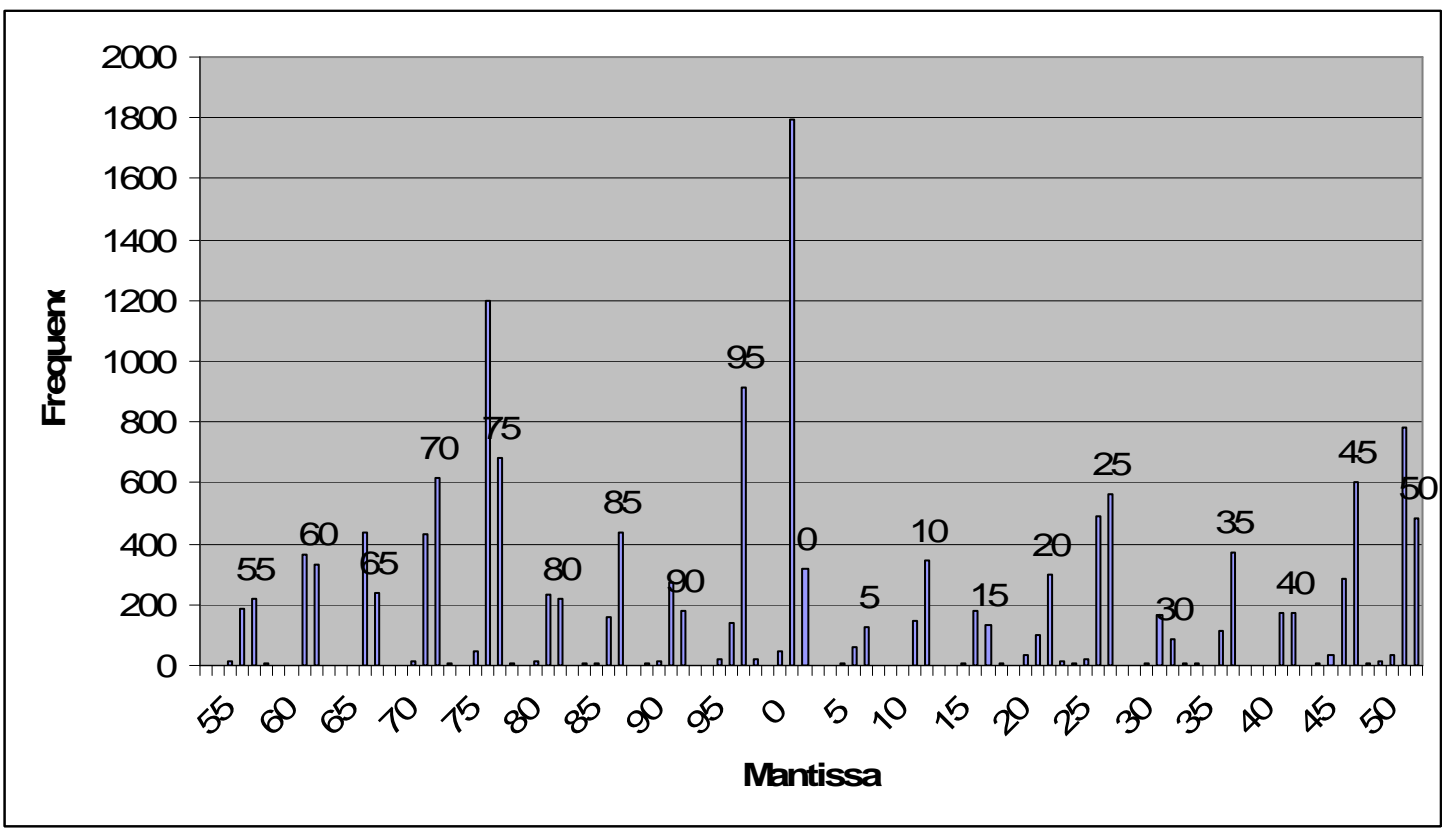


Table 2: Distribution of Interest Rates Above and Below Integers, Half points and Mid-points (percentages)

\begin{tabular}{|c|c|c|c|c|c|c|c|c|c|c|c|}
\hline & & $£ 1$ & $£ 500$ & $£ 1 \mathrm{~K}$ & $£ 2,500$ & $£ 5 K$ & $£ 10 K$ & $£ 25 \mathrm{~K}$ & $£ 50 K$ & $£ 100 K$ & Mortgage \\
\hline \multirow{6}{*}{$\begin{array}{l}\text { Integers, Half } \\
\text { Points and } \\
\text { Mid-points }\end{array}$} & Integers & 19.13 & 16.38 & 15.25 & 13.38 & 13.14 & 13.01 & 12.31 & 13.06 & 13.32 & 2.00 \\
\hline & Half Points & 18.08 & 14.05 & 13.51 & 12.03 & 11.95 & 11.54 & 10.94 & 11.07 & 11.48 & 3.20 \\
\hline & Quarters & 23.01 & 20.17 & 19.36 & 19.86 & 19.10 & 18.18 & 18.83 & 18.35 & 18.42 & 7.70 \\
\hline & Round numbers* & 9.06 & 12.10 & 12.94 & 13.76 & 13.81 & 15.07 & 13.91 & 14.17 & 14.47 & 6.67 \\
\hline & Other & 30.72 & 37.30 & 38.94 & 40.97 & 42.00 & 42.20 & 44.01 & 43.35 & 42.31 & 80.43 \\
\hline & $x^{2}$ & 91101.0 & 75604.0 & 57784.0 & 46617.0 & 38767.0 & 36242.0 & 38264.0 & 37566 & 38446.0 & 31827.00 \\
\hline \multirow{4}{*}{$\begin{array}{l}\% \text { of firms' } \\
\text { setting } \\
\text { interest rates } \\
\text { with Integers } \\
\text { and Half } \\
\text { Points }\end{array}$} & $\%$ firms using only Integers & 9.38 & 6.88 & 5.63 & 4.46 & 2.55 & 2.52 & 2.50 & 2.52 & 3.18 & 7.47 \\
\hline & $\begin{array}{l}\% \text { firms using only Half Points } \\
\% \text { firms using both Integers }\end{array}$ & 8.13 & 4.38 & 3.13 & 2.55 & 4.46 & 4.40 & 3.13 & 3.14 & 3.18 & 21.84 \\
\hline & $\begin{array}{l}\text { and Half Points } \\
\% \text { firms using neither Integers }\end{array}$ & 77.50 & 82.50 & 85.00 & 87.26 & 86.62 & 86.16 & 86.25 & 88.05 & 86.62 & 35.06 \\
\hline & or Half Points & 5.00 & 6.25 & 6.25 & 5.10 & 6.37 & 6.92 & 8.13 & 6.29 & 7.01 & 36.78 \\
\hline \multirow{3}{*}{$\begin{array}{c}50 \text { Basis } \\
\text { Points Above } \\
\text { and Below } \\
\text { Integers. }\end{array}$} & Above Integer & 22.57 & 26.51 & 27.63 & 28.58 & 28.46 & 29.64 & 29.01 & 29.55 & 29.70 & 34.50 \\
\hline & Below Integer & 17.21 & 22.89 & 24.24 & 26.15 & 27.35 & 27.62 & 28.92 & 27.97 & 27.08 & 60.30 \\
\hline & $\mathrm{X}^{2}$ & 52140.1 & 24044.1 & 8662.4 & 655.0 & 215.3 & 1656.8 & 2062.9 & 1561.5 & 698.8 & 1087.0 \\
\hline \multirow{5}{*}{$\begin{array}{l}25 \text { Basis } \\
\text { Points Above } \\
\text { and Below } \\
\text { Integers and } \\
\text { Half Points }\end{array}$} & Above Integer & 12.90 & 14.18 & 14.68 & 14.87 & 14.52 & 15.21 & 14.99 & 15.23 & 15.12 & 13.20 \\
\hline & Below Integer & 9.67 & 12.33 & 12.95 & 13.71 & 13.94 & 14.43 & 14.02 & 14.32 & 14.58 & 17.60 \\
\hline & Above Half Point & 9.05 & 11.90 & 12.46 & 13.42 & 14.00 & 14.03 & 14.94 & 14.22 & 14.04 & 26.00 \\
\hline & Below Half Point & 8.16 & 10.99 & 11.77 & 12.74 & 13.36 & 13.60 & 13.98 & 13.75 & 13.04 & 30.30 \\
\hline & $\underline{x}^{2}$ & 14482.0 & 10903.0 & 10950.0 & 9319.5 & .7765 .1 & 6151.9. & 4852.9. & 4747.4 & 4929.7 & 1273.5 \\
\hline \multirow{7}{*}{$\begin{array}{c}5 \text { Basis } \\
\text { Points Above } \\
\text { and Below } \\
\text { Integers, Half } \\
\text { Points and } \\
\text { Mid-Points }\end{array}$} & Above Integer and Half Point & 3.44 & 4.85 & 5.36 & 5.57 & 5.39 & 5.66 & 5.89 & 5.46 & 5.45 & 1.7 \\
\hline & Below Integer and Half Point & 3.33 & 4.53 & 4.58 & 5.54 & 5.60 & 5.58 & 5.62 & 5.70 & 5.23 & 28.0 \\
\hline & Above Mid-Point & 5.30 & 6.10 & 6.42 & 7.31 & 6.90 & 7.19 & 7.28 & 6.95 & 7.01 & 4.6 \\
\hline & Below Mid-Point & 3.93 & 5.60 & 6.26 & 6.70 & 6.85 & 6.94 & 7.05 & 6.74 & 6.97 & 17.2 \\
\hline & Above Round Numbers & 19.42 & 19.47 & 19.19 & 19.69 & 19.62 & 19.59 & 19.95 & 20.14 & 19.87 & 20.67 \\
\hline & Below Round Numbers & 18.59 & 18.88 & 18.74 & 19.69 & 19.73 & 19.41 & 20.09 & 19.16 & 19.42 & 14.49 \\
\hline & $\mathrm{X}^{2}$ & 171879 & 120104 & 79023.0 & 48561.0 & 37270.0 & 31062.0 & 30609.0 & 33143.0 & 35988.0 & 5292.6 \\
\hline
\end{tabular}

${ }^{*}$ Round numbers which are not integers, half points or quarters (e.g. $\left.0.2,0.4\right)$ 
Table 3: The Location of the First Decimal Placed Digit for Interest Rates for Mortgages and Different Quantities Deposited

\begin{tabular}{|c|c|c|c|c|c|c|c|c|c|c|c|c|c|}
\hline & & 0 & 1 & 2 & 3 & 4 & 5 & 6 & 7 & 8 & 9 & Sum & $\chi^{2}$ \\
\hline Mortgage & Freq. & & 814 & -1533 & 715 & -1843 & 1236 & 1430 & 2690 & 1160 & 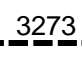 & 15414 & \multirow[t]{2}{*}{$4247.2^{* \star *}$} \\
\hline Rate & $\%$ & 4.70 & 5.30 & 9.90 & 4.60 & 12.00 & 8.00 & 9.30 & 17.50 & 7.50 & 21.20 & 100 & \\
\hline & Freq. & -4765 & -1848 & 3443 & -1099 & -1095 & -4578 & 1107 & 3094 & .1002 & 841 & 22872 & \multirow{2}{*}{$9415.9^{* * *}$} \\
\hline$£ 1$ & $\%$ & 20.83 & 8.08 & 15.05 & 4.81 & 4.79 & 20.02 & 4.84 & 13.53 & 4.38 & 3.68 & 100 & \\
\hline & Freq. & - 6247 & 2763 & _455 & -1968 & -2029 & -5488. & 2140 & 4225 & 1937 & 1660 & 33011 & \multirow{2}{*}{$7715.9^{* * *}$} \\
\hline$£ 500$ & $\%$ & 18.92 & 8.37 & 13.8 & 5.96 & 6.15 & 16.62 & 6.48 & 12.8 & 5.87 & 5.03 & 100 & \\
\hline & Freq. & 7672 & 3551 & -5846 & 2734 & -2657. & -6938. & 2855 & -5277_ & 2650 & 2289 & 42469 & \multirow[b]{2}{*}{$8529.0^{* \star *}$} \\
\hline$£ 1,000$ & $\%$ & 18.06 & 8.36 & 13.77 & 6.44 & 6.26 & 16.34 & 6.72 & 12.43 & 6.24 & 5.39 & 100 & \\
\hline & Freq. & 8364 & 4088 & 7240 & 3547 & 3335 & 7674 & 3621 & 6898 & 3432 & 3006 & 51205 & \multirow[t]{2}{*}{$8005.7^{* * *}$} \\
\hline$£ 2,500$ & $\%$ & 16.33 & 7.98 & $\overline{14.14}$ & 6.93 & 6.51 & 14.99 & $-\overline{7.07}$ & 13.47 & 6.7 & 5.87 & 100 & \\
\hline & Freq. & -9207 & 4605 & _7544 & -4048 & _3779 & 8431. & 4431 & _7544 & 3953 & 3579 & 57121 & \multirow{2}{*}{$7586.7^{* \star *}$} \\
\hline$£ 5,000$ & $\%$ & 16.12 & 8.06 & 13.21 & 7.09 & 6.62 & 14.76 & 7.76 & 13.21 & 6.92 & 6.27 & 100 & \\
\hline & Freq. & -9747 & 4932 & _8261 & -4255 & -4327 & -8832 & 4776 & -74887_ & -4406 & 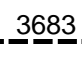 & 60706 & \multirow{2}{*}{$7532.3^{* \star *}$} \\
\hline$£ 10,000$ & $\%$ & 16.06 & 8.12 & 13.61 & 7.01 & 7.13 & 14.55 & 7.87 & 12.33 & 7.26 & 6.07 & 100 & \\
\hline & Freq. & 9412 & 4957 & 7912 & 4298 & 3987 & 8405 & 4982 & 8261 & 4393 & 3879 & 60486 & \multirow[t]{2}{*}{$6997.4^{* \star *}$} \\
\hline$£ 25,000$ & $\%$ & 15.56 & 8.2 & 13.08 & 7.11 & 6.59 & 13.9 & 8.24 & 13.66 & 7.26 & 6.41 & 100 & \\
\hline & Freq. & 9737. & 5088 & _7916 & 4243 & -4237 & 8351. & 4899 & _7594 & -4288 & 3871 & 60224 & \multirow{2}{*}{$6874.7^{\text {***}}$} \\
\hline$£ 50,000$ & $\%$ & 16.17 & 8.45 & 13.14 & 7.05 & 7.04 & 13.87 & 8.13 & 12.61 & 7.12 & 6.43 & 100 & \\
\hline & Freq. & 9684 & 4770 & 7821 & 4256 & 4119 & 8곤. & 4683. & 7381 & .4219 & 31 & 58585 & \multirow{2}{*}{$7614.32^{* * *}$} \\
\hline$£ 100,000$ & $\%$ & 16.53 & 8.14 & 13.35 & 7.26 & 7.03 & 14.29 & 7.99 & 12.6 & 7.2 & 5.6 & 100 & \\
\hline
\end{tabular}

$\chi^{2}$ goodness of fit tests ${ }^{* *}$ significant at $0.01 \%$ 
Table 4: The Location of the Second Decimal Placed Digits for Interest Rates for Mortgages and Different Quantities Deposited

\begin{tabular}{|c|c|c|c|c|c|c|c|c|c|c|c|c|c|}
\hline & & 0 & 1 & 2 & 3 & 4 & 5 & 6 & 7 & 8 & 9 & Sum & $\chi^{2}$ \\
\hline Mortgage & req. & 3050 & 28 & 17 & 132 & _3175 & 4219 & 53 & 29 & 199 & 4512 & 15414 & \multirow{2}{*}{$21956.6^{* * *}$} \\
\hline nate & $\%$ & 19.79 & 0.18 & 0.11 & 0.86 & 20.60 & 27.37 & 0.34 & 0.19 & 1.29 & 29.27 & 100 & \\
\hline & Freq. & 13161 & 92 & 67 & 134 & 94 & 9011 & 76 & 59 & 103 & 85 & 22882 & \multirow{2}{*}{$88330.7^{* * *}$} \\
\hline$£ 1$ & $\%$ & 57.52 & 0.40 & 0.29 & 0.59 & 0.41 & 39.38 & 0.33 & 0.26 & 0.45 & 0.37 & 100 & \\
\hline & Freq. & 18212 & 197 & 137 & 144 & 202 & 13540 & 161 & 94 & 140 & 131 & 32958 & \multirow{2}{*}{$123361.9^{* *}$} \\
\hline$£ 500$ & $\%$ & 55.26 & 0.60 & 0.42 & 0.44 & 0.61 & 41.08 & 0.49 & 0.29 & 0.42 & 0.40 & 100 & \\
\hline & Freq. & 23305 & 222 & 197 & 277 & 233 & 17337 & 218 & 117 & 254 & 176 & 42336 & \multirow[t]{2}{*}{$157038.2^{* *}$} \\
\hline$£ 1,000$ & $\%$ & 55.05 & 0.52 & 0.47 & 0.65 & 0.55 & 40.95 & 0.51 & 0.28 & 0.60 & 0.42 & 100 & \\
\hline & Freq. & 26864 & 273 & 198 & 380 & 396 & 21594 & 354 & 205 & 294 & 313 & 50871 & \multirow[t]{2}{*}{$182806.7^{* * *}$} \\
\hline$£ 2,500$ & $\%$ & 52.81 & 0.54 & 0.39 & 0.75 & 0.78 & 42.45 & $0 . \overline{70}$ & $0 . \overline{40}$ & $0 . \overline{8}$ & 0.62 & 100 & \\
\hline & Freq. & 299927 & 274 & 167 & 410 & 390 & 23979 & -454 & 290 & 359 & -370 & 5666으. & \multirow{2}{*}{$203287.6^{* * *}$} \\
\hline$£ 5,000$ & $\%$ & 52.86 & 0.48 & 0.29 & 0.72 & 0.69 & 42.35 & 0.80 & 0.51 & 0.63 & 0.65 & 100 & \\
\hline & Freq. & 31910 & 313 & 218 & 465 & _464 & 25152 & 412 & 363 & 476 & 371 & 60144 & \multirow[t]{2}{*}{$214549.0^{* * *}$} \\
\hline$£ 10,000$ & $\%$ & 53.06 & 0.52 & 0.36 & 0.77 & 0.77 & 41.82 & 0.69 & 0.60 & 0.79 & 0.62 & 100 & \\
\hline & Freq. & 30731 & 283 & 329 & 505 & 445 & 25577 & 378 & 395 & 467 & 462 & 59572 & \multirow{2}{*}{$209002.0^{* * *}$} \\
\hline$£ 25,000$ & $\%$ & 51.59 & 0.48 & 0.55 & 0.85 & 0.75 & 42.93 & 0.63 & 0.66 & 0.78 & 0.78 & 100 & \\
\hline & Freq. & 31253 & 328 & 292 & 462 & 531 & 24978 & -445 & 329 & 372 & 370 & 59360 & \multirow[t]{2}{*}{$210505.3^{* \star *}$} \\
\hline$£ 50,000$ & $\%$ & 52.65 & 0.55 & 0.49 & 0.78 & 0.89 & 42.08 & 0.75 & 0.55 & 0.63 & 0.62 & 100 & \\
\hline & Freq. & 30406 & 363 & 269 & 466 & 486 & 24001 & 454 & 301 & 414 & 370 & 57530 & \multirow[t]{2}{*}{$203522.5^{* * *}$} \\
\hline$£ 100,000$ & $\%$ & 52.85 & 0.63 & 0.47 & 0.81 & 0.84 & 41.72 & 0.79 & 0.52 & 0.72 & 0.64 & 100 & \\
\hline
\end{tabular}


Table 5: The Influence of the Average and Dispersion of Market Interest Rates and Ownership on Interest Rate Clustering

\begin{tabular}{|c|c|c|c|c|c|c|c|c|c|c|c|}
\hline & Value Deposited & $£ 1$ & $£ 500$ & $£ 1 K$ & $£ 2,500$ & $£ 5 K$ & $£ 10 K$ & $£ 25 K$ & $£ 50 K$ & $£ 100 \mathrm{~K}$ & Mortgage \\
\hline \multirow{9}{*}{$\begin{array}{l}\bar{\Xi} \\
\mathbb{D} \\
\mathbb{D} \\
\mathbb{D} \\
\bar{N}\end{array}$} & Constant & $\begin{array}{c}-0.750^{*} \\
(0.05)\end{array}$ & $\begin{array}{c}-0.853^{*} \\
(0.04)\end{array}$ & $\begin{array}{c}-0.918^{*} \\
(0.04)\end{array}$ & $\begin{array}{l}-1.013^{*} \\
(0.034)\end{array}$ & $\begin{array}{l}-1.057^{*} \\
(0.032)\end{array}$ & $\begin{array}{l}-0.989^{*} \\
(0.031)\end{array}$ & $\begin{array}{l}-1.079^{\star} \\
(0.032)\end{array}$ & $\begin{array}{l}-1.057^{*} \\
(0.032)\end{array}$ & $\begin{array}{l}-1.045^{\star} \\
(0.032)\end{array}$ & $\begin{array}{l}-0.855^{*} \\
(0.111)\end{array}$ \\
\hline & Mutual & $\begin{array}{l}-0.014 \\
(0.02)\end{array}$ & $\begin{array}{r}-0.012 \\
(0.02)\end{array}$ & $\begin{array}{l}-0.009 \\
(0.015)\end{array}$ & $\begin{array}{l}-0.025^{*} \\
(0.014)\end{array}$ & $\begin{array}{c}-0.004 \\
(0.0137)\end{array}$ & $\begin{array}{l}-0.023^{*} \\
(0.001)\end{array}$ & $\begin{array}{c}-0.030^{\star} \\
(0.01)\end{array}$ & $\begin{array}{l}-0.012 \\
(0.013)\end{array}$ & $\begin{array}{l}-0.019 \\
(0.013)\end{array}$ & $\begin{array}{l}-0.372^{*} \\
(0.049)\end{array}$ \\
\hline & e Market Rate & $\begin{array}{c}-0.021^{*} \\
(0.01)\end{array}$ & $\begin{array}{l}-0.022^{*} \\
(0.007)\end{array}$ & $\begin{array}{l}-0.019^{*} \\
(0.006)\end{array}$ & $\begin{array}{l}-0.015^{*} \\
(0.005)\end{array}$ & $\begin{array}{l}-0.011^{*} \\
(0.005)\end{array}$ & $\begin{array}{l}0.023^{*} \\
(0.005)\end{array}$ & $\begin{array}{l}0.0113^{*} \\
(0.006)\end{array}$ & $\begin{array}{l}0.011^{*} \\
(0.006)\end{array}$ & $\begin{array}{l}0.0102^{*} \\
(0.006)\end{array}$ & $\begin{array}{l}-0.178^{*} \\
(0.019)\end{array}$ \\
\hline & $\begin{array}{c}\text { Market Rate Standard } \\
\text { Deviation }\end{array}$ & $\begin{array}{l}0.005 \\
(0.21)\end{array}$ & $\begin{array}{l}0.016 \\
(0.02)\end{array}$ & $\begin{array}{c}0.014 \\
(0.016)\end{array}$ & $\begin{array}{l}-0.030 \\
(0.016)\end{array}$ & $\begin{array}{l}-0.004 \\
(0.014)\end{array}$ & $\begin{array}{l}0.0163 \\
(0.014)\end{array}$ & $\begin{array}{l}-0.0114 \\
(0.0151)\end{array}$ & $\begin{array}{c}0.008 \\
(0.014)\end{array}$ & $\begin{array}{l}0.0037 \\
(0.015)\end{array}$ & $\begin{array}{l}-1.424^{*} \\
(0.565)\end{array}$ \\
\hline & Total Observations & 22872 & 33011 & 42469 & 51205 & 57121 & 60706 & 60486 & 60238 & 58585 & 15414 \\
\hline & Wald $\chi^{2}$ & $7.19^{*}$ & $11.08^{*}$ & $10.04^{*}$ & $10.03^{*}$ & 4.77 & $21.44^{*}$ & 9.57 & 5.11 & 5.38 & 126.45 \\
\hline & Pseudo $\mathrm{R}^{2}$ & 0.0003 & 0.0004 & 0.0003 & 0.0002 & 0.0001 & 0.0004 & 0.0002 & 0.0001 & 0.0001 & 0.0481 \\
\hline & Log Pseudo Likelihood & -11171 & -14716 & -18136 & -20144 & -22222 & -23457 & 55887 & -23339 & -22986 & -1455 \\
\hline & Likelihood Ratio $\chi^{2}$ & $299.56^{*}$ & 267.25 & 258.92 & 277.12 & 256.50 & 236.60 & 277.72 & 223.08 & 218.99 & $713.80^{*}$ \\
\hline \multirow{9}{*}{ 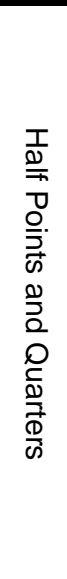 } & Constant & $\begin{array}{l}-0.090^{*} \\
(0.04)\end{array}$ & $\begin{array}{c}-0.320^{\star} \\
(0.03)\end{array}$ & $\begin{array}{l}-0.362^{*} \\
(0.03)\end{array}$ & $\begin{array}{l}-0.410^{*} \\
(0.028)\end{array}$ & $\begin{array}{l}-0.437^{*} \\
(0.027)\end{array}$ & $\begin{array}{l}-0.508^{*} \\
(0.026)\end{array}$ & $\begin{array}{l}-0.495^{\star} \\
(0.0263)\end{array}$ & $\begin{array}{l}-0.506 \\
(0.026)\end{array}$ & $\begin{array}{l}-0.474^{*} \\
(0.027)\end{array}$ & $\begin{array}{l}-0.824^{\star} \\
(0.069)\end{array}$ \\
\hline & Mutual & $\begin{array}{l}0.025 \\
(0.01)\end{array}$ & $\begin{array}{l}0.013 \\
(0.01)\end{array}$ & $\begin{array}{c}-0.006 \\
(0.01)\end{array}$ & $\begin{array}{l}-0.009 \\
(0.011)\end{array}$ & $\begin{array}{l}-0.001^{*} \\
(0.011)\end{array}$ & $\begin{array}{l}0.0126 \\
(0.011)\end{array}$ & $\begin{array}{l}0.012^{*} \\
(0.011)\end{array}$ & $\begin{array}{l}-0.0136 \\
(0.011)\end{array}$ & $\begin{array}{l}-0.008^{*} \\
(0.011)\end{array}$ & $\begin{array}{l}0.0388 \\
(0.027)\end{array}$ \\
\hline & Average Market Rate & $\begin{array}{c}-0.028^{*} \\
(0.01)\end{array}$ & $\begin{array}{l}-0.018^{*} \\
(0.006)\end{array}$ & $\begin{array}{l}0.014^{*} \\
(0.005)\end{array}$ & $\begin{array}{l}-0.013^{*} \\
(0.004)\end{array}$ & $\begin{array}{l}-0.011^{*} \\
(0.005)\end{array}$ & $\begin{array}{l}0.0583^{*} \\
(0.005)\end{array}$ & $-0.083^{*}$ & $\begin{array}{l}0.0005 \\
(0.004)\end{array}$ & $0.009^{*}$ & $\begin{array}{l}-0.0791^{*} \\
(0.0119)\end{array}$ \\
\hline & $\begin{array}{l}\text { Market Rate Standard } \\
\text { Deviation }\end{array}$ & $\begin{array}{c}0.003 \\
(0.019)\end{array}$ & $\begin{array}{r}0.013 \\
(0.015)\end{array}$ & $\begin{array}{r}-0.0003 \\
(0.014)\end{array}$ & $\begin{array}{c}0.003 \\
(0.0127)\end{array}$ & $\begin{array}{l}-0.005 \\
(0.012)\end{array}$ & $\begin{array}{l}0.0122 \\
(0.0121)\end{array}$ & $\begin{array}{c}0.007 \\
(0.012)\end{array}$ & $\begin{array}{r}0.012 \\
(0.012)\end{array}$ & $\begin{array}{c}0.007 \\
(0.012)\end{array}$ & $\begin{array}{l}-0.0304 \\
(0.031)\end{array}$ \\
\hline & Total Observations & 22872 & 33011 & 42469 & 51205 & 57121 & 60706 & 60486 & 60238 & 58585 & $15414^{*}$ \\
\hline & Wald $\chi^{2}$ & $16.97^{*}$ & $9.69^{*}$ & $4^{*}$ & $2^{*}$ & 5.17 & 4.09 & 4.60 & 3.57 & 4.50 & 49.88 \\
\hline & Pseudo $\mathrm{R}^{2}$ & 0.0005 & 0.0002 & 0.0001 & 0.0001 & 0.0001 & 0.0001 & 0.0001 & 0.0000 & 0.0001 & 0.0045 \\
\hline & Log Pseudo Likelihood & -15486 & -21205 & -26894 & -32052 & 35385 & -36936 & -36824 & -36497 & -35736 & -5270 \\
\hline & Likelihood Ratio $\chi^{2}$ & $304.4^{*}$ & 266.3 & 283.92 & 274.88 & 301.25 & 275.08 & 278.63 & 319.35 & 320.94 & $902.75^{*}$ \\
\hline
\end{tabular}

* Statistically significant at 10 per cent. Robust Standard Errors employed. 


\subsection{The Distribution of Interest Rates}

The distribution of interest rates at, above and below integers, half points, quarters, and round numbers, is reported in Table 2. This analysis of interest rate observations is undertaken for mortgages and different deposit quantities for, a) observations at integers, half points, quarters and round numbers, and the distribution above and below these points, by b) 50 basis points, c) 25 basis points and, d) 5 basis points. Further, the proportion of firms which set interest rates at reference points is also recorded. In all cases the random distribution of interest rates is rejected at a high level of statistical significance using a $\chi^{2}$ goodness of fit test.

Deposit interest rate observations at integers, half points and at quarters occur in $40 \%$ to $60 \%$ of all observations. For all quantities deposited, there are lower levels of integers, half and quarter observations as the value of the deposit increases. Integers, half points, quarters and round numbers do not frequently occur for mortgages and are recorded in less than $20 \%$ of observations. The proportion of firms setting interest rates using integers and half points also varies substantially between deposits and mortgages. Over $75 \%$ of deposit issuing firms set interest rates using both integers and half points, compared with $35 \%$ of all mortgage issuing firms.

More deposit interest rate observations are located in the 50 basis points range above integers than below integers for all quantities invested. Similarly, more deposit interest rate observations are located in the 25 basis points range above integers and half points than below these points. When a 5 basis points range is examined in relation to integers, half points and mid-points, the deposit rate observations have a very strong tendency to be above rather than below the reference points. The finding that deposit rates are more likely to be above rather than below reference points is supportive of the hypothesis that some depositors engage in naïve rounding. 
More mortgage interest rate observations are distributed in the 50 basis points range below integers (60\% of total) than are recorded above integers. More mortgage observations are recorded in the 25 basis points range below integers and half points $(47 \%)$ than above these points $(39 \%)$. Overwhelmingly more mortgage observations are recorded in the 5 basis points range below integers and half points $(28 \%)$ than above them (1.7\%), and a similar pattern is evident for mid-points. The finding that mortgage rates are more likely to be below rather than above reference points is supportive of both the naïve truncation and naïve rounding hypotheses.

The distribution of interest rate observations that are 5 basis points above and below integers, half points, quarters and round numbers indicates only a small proportion of all deposit observations are included in this distribution; a proportion which increases with the size of the deposit invested. The random distribution of interest rate clustering is rejected in all cases using $\chi^{2}$ goodness of fit tests at high levels of statistical significance. The location of the first decimal placed digit in deposit rates indicates that the numbers 0 and 5 are the most frequently recorded numbers (in 30 to $50 \%$ of cases) for all quantities deposited. The use of these digits declines as the size of funds deposited increases. The digits 2 and 7 together account for $30 \%$ of first decimal place number deposit rate observations. The most frequently observed first decimal placed numbers in mortgage rates are $9(21 \%), 7(17 \%), 4(12 \%)$ and $2(9 \%)$, with numbers $0,1,3$ and 8 being used in around $27 \%$ of observations. Clustering in mortgages occurs just below reference points in most observations. This location of digits is consistent with truncation and rounding being used by borrowers.

The most frequently recorded second decimal placed digits for deposit rates is 0 and 5 , which account for around $95 \%$ of all observations. This finding is consistent with truncation and rounding as the presence of '0's would indicate integers, half points and quarters. The location of second digit mortgage rate numbers indicates the numbers 9 and 4 are recorded in just under, $50 \%$ of 
observations. This distribution is consistent with the setting of a large proportion of interest rates just below integers and half points.

\subsection{The Influence of External or Environmental Factors on Clustering}

The assessment of the influence of the external factors on the degree of clustering is reported in Table 5. This assessment indicates that both the average level of market interest rates is significantly associated with the degree of interest rate clustering. In most cases for the clustering at integers and quarters and half points, positive and statistically significant coefficients are recorded for the average market rate. The dispersion of market rates (denoted market rate standard deviation) is significant in only one case, indicating that the dispersion of market rates is not influential on interest rate clustering.

Lastly, the variable, Mutual, which indicates whether a firm is, or is not, mutually owned and does not profit maximise, is negatively signed in most and significant in some cases for clustering at integers and quarter and half points. This indicates that mutual ownership (non profit-maximising) is very weakly negatively associated with the degree of clustering at these pricing points. Overall the model fit indicated by the diagnostic statistics is poor for all estimations indicating that external factors alone provide a poor explanation for the interest rate clustering observed in the sample.

\subsection{Summary Comments}

From this analysis a number of findings can be reported. Initially, a substantial degree of interest rate clustering occurs in UK deposit and mortgage markets. Most interest rate clustering occurs in a manner consistent with the predictions of our model. Only $5 \%$ of firms setting deposit interest rates use neither integers nor half points and thus do not appear to maximise profits in the manner predicted by our model. It is clear that in addition to integers and half points, other reference points, particularly quarters, are points of clustering in a manner congruent with the model predictions. In summary, it appears that both rounding and truncation 
are influential on clustering, being accommodated most frequently together by interest rate setters. This indicates interest rate clustering occurs in a manner consistent with customers using both rounding and truncation as predicted in cases 3 and 6 . The location and the distribution of most interest rate observations occurs in a form predicted for both deposits and mortgages. For deposit rates, most clustering is recorded at integers and half points, and most clustering in mortgage rates is observed 5 basis points below these points. In addition, the distribution of rates above and below reference points is as predicted by the models incorporating both truncation and rounding. Further, the degree of interest rate clustering varies with the amount of funds invested, indicating that clustering affects smaller savers to a greater degree, consistent with the predictions of previous commentators (e.g. Grossman and Stiglitz 1980). Lastly, the degree of clustering is positively associated with the level of market interest rates and occurs to a greater extent in profit-maximising firms. In summary, the form of interest rate clustering observed is consistent with banks maximising returns from customers who favour truncation and rounding of numbers to assist limitations in number recall.

\section{Conclusions}

Much current academic explanation of interest rate or price clustering views this phenomenon as a benign feature of retail markets. This indicates that price clustering results from either structural factors outside the control of the firm or behavioural factors, which allow the price setter to use clustering in a sympathetic manner to assist customer decision-making or firm actions have dominated current understandings. This study develops and re-directs this literature, proposing that price and interest rate clustering develops in a manner consistent with price setters maximising the return possible from those customers least able to recall and process the number information contained in prices or interest rates. Both a theoretical justification and empirical evidence for this interpretation of interest rate clustering in the context of UK financial services 
markets is provided. Within the conclusions the principal findings of the study, the policy implications of this work and suggestions for future research are discussed.

We report that clustering of retail interest rates around a limited number of digits is highly significant in the UK deposit and mortgage markets. The degree and form of interest rate clustering are recorded in a manner congruent with the interest rate setters maximising returns from customers who both round and truncate numbers. This finding provides international evidence supportive of Kahn et al (1999), who indicated US banks set retail deposit interest rates in a form consistent with maximising returns from customers who employ only truncation strategies. This study, extends the work of Kahn et al (1999) by also investigating whether a) the degree of financial involvement is significant in interest rate clustering, b) the use of another number processing strategy, rounding, was significant in these markets, and c) if the predictions of the theory originally forwarded by Kahn et al (1999), can be applied to both lending and deposit markets.

We report that the degree of financial involvement of the customer, represented by the monetary value of deposits, has a substantial influence on the degree of interest rate clustering. Specifically, interest rate clustering is exaggerated for deposits of smaller monetary values. This finding is consistent with the view that smaller investors have a poorer comprehension of financial products than larger investors, a point supported by contemporary UK survey evidence (FSA 2006). Secondly, the significance of rounding, in addition to truncation, as a numberprocessing strategy used by naïve investors and borrowers to reduce the effects of limited number recall, is examined. Most interest rate observations appear to cluster in a manner consistent with naïve customers who truncate and round numbers together. Third, the form of interest rate clustering observed in deposit and mortgage markets differs as predicted. Deposit rates tend to cluster at integers and other key reference points. Conversely, the clustering of mortgage 
interest appears to occur just below such key reference points. In addition, the distribution of both deposit and mortgage rates above and below reference points is in accord with predictions. Lastly, interest rate clustering in the form predicted is marginally undertaken by profit-maximising firms to a greater extent relative to firms which do not explicitly maximise returns from customers. Further, the degree of retail interest rate clustering appears to be positively associated with market interest rates.

The implications of these findings are multifaceted. Indeed, how we identify behavioural traits and structure institutions to help us accommodate these biases in consumer decision-making is a key policy challenge (Kopcke et al 2004). Behavioural strategies used by consumers are particularly important as the present UK system of financial regulation forwards consumer protection as a paramount regulatory concern (Llewellyn, 2000, Franks et al 2003). This concern has formed as many financial services customers, in the UK at least, are relatively poor at processing number information and comprehending financial products (FSA 2006). This emphasis on consumer protection, while different from the common practice of financial regulation in many developed nations raises a number of specific UK policy concerns.

Consequently the regulation of how UK financial firms promote their business to customers places great importance on how a financial product is sold, and indicates a sale should only occur when the customer is satisfied that the product sold is appropriate for their needs and the characteristics of the product have been clearly transmitted. Cases of financial services firms misleading customers through the interest rate setting policies have already been observed in the UK, providing anecdotal evidence that financial services firms may indeed set interest rates to mislead consumers. For example, the Office of Fair Trading has previously reported problems in the pricing of deposit accounts (OFT 1998), credit cards (OFT 2002a, 2006) and store cards (OFT 2002b), within the last 10 years. Further, it can also be inferred that the potential legal liability of firms 
engaged in such misleading activity could be substantial (see Hanson and Kysar 1999).]

In response to these concerns a measured policy response would accommodate the material choice and quality concerns of all potential consumers, not just those who may be more or less able to make informed and rational decisions within mortgage and deposit markets (see Thaler and Sunstein 2003). From our assessment, if a proportion of customers are naïve up to 99 basis points may be lost through truncation and up to 50 may be lost by rounding, providing a small yet significant loss to naïve customers who have limited recall. Further the provision of clustered interest rates provides little obvious cost to sophisticated customers who are not affected by problems of limited recall. The benefits from the current practice of price or interest rate clustering appear to be generally received by the price setter. The effect of changing this current pricing practice appears to be low to implement, involving the resetting of interest rates which already change with some regularity. To summarise, there may be a clear public welfare case to more closely observe the interest rates and indeed prices firms set in a clustered manner to maximise returns from customers with lower levels of financial involvement.

Such an interventionist approach to amending the practice of interest rate setting may also have a range of negative effects on this market. Amending for the limitations of one group of consumer, such as more naïve consumers could potentially reduce opportunities and choice of other less naïve consumers (Michell 2005). Any policy which reduces the choices or materially disadvantages one group relative to another through a form of redistribution, is to be avoided (Michell 2005). Indeed adopting a policy position which undermines the assumption that individuals are the best judges and protectors of their own welfare can potentially lead to unwelcome illiberal externalities. 
In light of our discussion, price and interest rate clustering is an area which would benefit from further academic investigation. The proposition that interest rate or price clustering emerges from a motivation to maximise profits requires further academic work to assess the consistency of this explanation. In particular, analysis of other markets where some customers have difficulties in assessing product price and quality, as seen in retail financial services, would benefit from further research.

To conclude, interest rate clustering in retail banking markets is viewed to arise from interest rate setters maximising returns from more naïve and less informed customers - customers who are least able to recall and process number information accurately. The form of clustering within this manner appears to be exaggerated when low levels of financial involvement are concerned. It is concluded that this form of interest rate or price clustering is an area which demands further academic consideration, policy discussion and potentially regulatory investigation. 


\section{References}

Ahn, H. J., Cai, J., and Cheung, Y. L (2005). "Price Clustering on the limit-order book: Evidence from the Stock Exchange of Hong Kong", Journal of Financial Markets, vol.8, pp.421-451.

Anderson, E. T. and Simester, D. I. (2003). "Effects of \$9 Price Endings on Retail Sales: Evidence from Field Experiments", Quantitative Marketing and Economics, vol.1, pp.93-110.

Ap Gwilym, O., Claire, A. and Thomas, S. (1998). "Extreme price clustering in the London equity index futures and options markets", Journal of Banking and Finance, vol.22, pp.1193-1206.

Ap Gwilym, O. and Alibo E. (2003). "Decreased Price Clustering in FTSE 100 Futures Contracts Following a Transfer from Floor to Electronic Trading", The Journal of Futures Markets, vol. 23, no.7, pp.647-659.

Ap Gwilym, O., McManus, I., and Thomas, S. (2005). "Fractional Versus Decimal Pricing: Evidence from the UK long Gilt Market", The Journal of Futures Markets, vol. 25, no.5, pp.419-442.

Ashcraft, M. H. (1992) "Cognitive arithmetic: A review of the data and theory" Cognition, vol.44, pp.75-106.

Ashton, J. K. and S. Letza, (2003). "The Differential Returns Offered by Mutually Owned and Proprietary UK Depository Institutions: 1993-2000", The Annals of Public and Cooperative Economics, vol.74, no.2, pp.183-204.

Ashworth, J., Heyndels, B. and Smolders, S. (2003). "Psychological taxing in Flemish municipalities", Journal of Economic Psychology, vol.24, pp.741-762.

Basu, K. (2006). "Consumer Cognition and Pricing in the Nines in Oligopolistic Markets", Journal of Economics and Marketing Strategy, vol.15, no.1, pp. 125141.

Berger, A. N. and Hannan, T. H. (1989). The Price Concentration Relationship in Banking", The Review of Economics and Statistics, vol.71, no.2, pp.291-299.

Bizer, G. Y. and Schindler, R. M. (2005). "Direct Evidence of Ending-Digit DropOff in Price Information Processing", Psychology and Marketing, vol.22, no.10, pp.771-783. 
Brown, P. Chua, A. and Mitchell, J. (2002). "The influence of cultural factors on price clustering: Evidence from Asia-Pacific stock markets", Pacific Basin Finance Journal, vol.10, pp.307-332.

Butler, D. and Loomes, G. (1988). "Decision Difficulty and Imprecise Preferences", Acta Psychologica, vol.68, pp. 183-196.

Camarer, C., Issacharoff, S. Lowenstein, G., O'Donoghue T. and Rabin, M. (2003). "Regulation for Conservatives: Behavioural Economics and the Case for Asymmetric Paternalism", University of Pennsylvania Law Review, vol.151, no.3, pp. 1211-1254.

Christie, W. G. and Schultz, P. H. (1994). "Why do NASDAQ Market Makers Avoid Odd-Eight Quotes?", The Journal of Finance, vol. 49, no. 5, pp.1813-1840. Christie, W. G., Harris, J. H. and Schultz, P. H. (1994). "Why did NASDAQ Market Makers Stop Avoiding Odd-Eight Quotes?", The Journal of Finance, vol. 49, no. 5, pp.1841-1860.

Chung, K. H., Van Ness B. F. and Van Ness R. A. (2004). "Trading Costs and Quote Clustering on the NYSE and NASDAQ after Decimalization", The Journal of Financial Research, vol.27, no.3, pp.309-328.

Cooney J. W, Van Ness, B, and Van Ness, R. (2003). "Do investors prefer eveneighth prices? Evidence from NYSE limit orders", Journal of Banking and Finance, vol.27, pp.719-748.

Costanzo L and Ashton. J. K. ( 2006) "Product Innovation and Consumer Choice in the UK Financial Services Industry", Journal of Financial Regulation and Compliance, vol.14, no.3. pp.285-303.

Das, S. and Zhang, H. (2003). "Rounding-up in reported EPS, behavioural thresholds and earnings management", Journal of Accounting and Economics, vol. 35, pp.31-50.

Dehaene, S. (2001) "Précis of the Number Sense", Mind and Language, vol.16, no.1, pp.16-36.

Dehaene, S. and Mehler, J. (1992) "Cross-linguistic regularities in the frequency of number words", Cognition, vol.43, p.1-29. 
Diebold, F. X. and Sharpe, S. A. "Post Deregulation Bank Deposit Rate Pricing The multivariate Statistics", Journal of Business and Economic Statistics, vol.8, no.3, pp. 281-291.

Financial Services Authority. (2006) Financial Capability in the UK: Establishing a Baseline, The Financial Services Authority, London.

Franks, J., Mayer C and Correia da Silva, L. (2003) Asset Management and Investor Protection: An International Analysis, Oxford University Press, Oxford. Grossman, S. J., Miller, M. H, Cone, K. R., Fischel, D. R, and Ross, D. J. (1997). "Clustering and Competition in Assets Markets", Journal of Law and Economics, vol.40, p.23-60.

Grossman, S. J. and Stiglitz, J. (1980). "On the Impossibility of Informationally Efficient Markets", The American Economic Review, vol.70, no.3, pp.393-408. Hannan, T. H. and Liang, J. N. (1993). "Inferring Market Power from Time Series Data", International Journal of Industrial Organization, vol.11, no.2, pp.205-218. Hanson, J. D. and Kysar, D. A. (1999). "Taking Behavioralism Seriously: Some Evidence of Market Manipulation”, Harvard Law Review, vol.112, no.7, pp.14201572.

Heffernan, S.A. (1997). "Modelling British Interest Rate Adjustment: An Error Correction Approach", Economica, vol. 64, no. 254, pp. 211-231.

Heffernan, S. A. (2002). "How do UK financial institutions really price their banking products?", Journal of Banking and Finance, vol. 26, no.10, pp. 19972016.

Huang R. D. and Stoll, H. R. (2001). "Tick Size, Bid Ask Spreads, and Market Structure", Journal of Financial and Quantitative Analysis, vol. 36, no.4, pp. 503522.

International Monetary Fund (2003), "IMF Reviews the Experience with the Financial Sector Assessment Programme and Reaches Conclusions on Issues Going Forward", available from www.imf.org.

Jackson W.E. (1997). "Market Structure and the speed of price adjustments:

Evidence of non-monotonicity", Review of Industrial Organization, vol.12, no.1, pp.37-57. 
Kahn, C., Pennacchi, G. and Sopranzetti, B. (1999). "Bank Deposit Rate Clustering: Theory and Empirical Evidence", The Journal of Finance, vol.54, no.6, pp.2185-2214.

Kahneman, D. and Tversky, A. (1979). "Prospect Theory - Analysis of Decision Under Risk", Economica, vol.47, no.2, pp.263-292.

Kandel, S., Sarig, O. and Wohl, A. (2001). "Do investors prefer round stock prices? Evidence form Israeli IPO auction", Journal of Banking and Finance, vol.25, pp. 1543-1551.

Kopcke, R. W., Sneddon Little J. and Tootell, G. M. B. (2004) "How Humans Behave: Implications for Economics and Economic Policy", New England Economic Review, no.1, pp.3-35.

Llewellyn, D. T. (2000). "Financial Regulation: A Perspective form the United Kingdom", Journal of Financial Services Research, vol.17, no.1, pp.309-317.

Mazumdar, T., Raj, S. P. and Sinha, I. (2005). "Reference Price Research: Review and Propositions", Journal of Marketing, vol.69, pp.84-102.

Michell, G. (2005). "Libertarian Paternalism is an Oxymoron", Northwestern University Law Review, vol.99, no.3, pp.1245-1277.

Mitchell, J. (2001). "Clustering and Psychological Barriers: The Importance of Numbers", The Journal of Futures Markets, vol.21, no.5, pp.395-428.

Neumark, D. and Sharpe, S. A. (1992). "Market Structure and the Nature of Price Rigidity - Evidence from the market for consumer deposits", Quarterly Journal of Economics, vol.107, no.2, pp. 657-680.

Niederhoffer, V. (1966). "A New Look at Clustering of Stock Prices", Journal of Business, vol.39, no. 2, pp. 309-313.

Office of Fair Trading. (1998). "Bridgeman Warns Banks about Unfair Contract Terms, PN 21/98, 15th May, London.

Office of Fair Trading, (1999) Vulnerable Consumers and Financial Services, The Report of the Director General's Inquiry, Office of Fair Trading, London.

Office of Fair Trading. (2002a). "Major Credit Card Companies Agree to Change Adverts", PN 10/02, 20th February, London. 
Office of Fair Trading. (2002b). "Companies Amend Misleading Interest Free Credit Ads", PN 20/02, 24th April, London.

Office of Fair Trading, (2006) "Calculating fair default charges in credit cared contracts: A statement of the OFT's position", Office of Fair Trading Statement OFT 842, London.

Ohta, W. (2006). "An analysis of intraday patterns in price clustering on the Tokyo Stock Exchange", Journal of Banking and Finance, vol.30, pp.1023-1039.

Palmon, O., Smith B. A., and Sopranzetti, B. J. (2004). "Clustering in Real Estate Prices, Determinants and Consequences", Journal of Real Estate Research, vol.26, no.2, pp. 115-136.

Salop, S. and Stiglitz, J. (1977). "Bargains and Ripoffs: A Model of Monopolistically Competitive Price Dispersion”, Review of Economic Studies, vol. 44, no.3, pp. 493-510.

Schindler, R. M. (2001). "Relative Price Level of 99 Ending Prices: Image versus Reality", Marketing Letters, vol.12, no.3, pp. 239-247.

Schindler, R. M. and Wimin, A. R. (1989). "Effects of Odd Pricing on Price Recall", Journal of Business Research, vol.19, pp.165-177.

Shafir, E., Diamond, P. Tversky, A. (1997). "Money Illusion”, The Quarterly Journal of Economics, vol.112, No.2, pp.341-374.

Sonnemans, J. (2006). "Price clustering and natural resistance points in the Dutch stock market: A natural experiment”, European Economic Review, in press and forthcoming.

Sopranzetti B. J. and Datar, V. (2002). "Price Clustering in Foreign Exchange Markets", Journal of Financial Markets, vol.5, no.4, pp.411-417.

Striving, M. (2000). "Price Endings When Prices Signal Quality", Management Science, vol.46, no.12, pp.1617-1629.

Thaler, R. H. and Sunstein, C. R. (2003). "Libertarian Paternalism", American Economic Review, vol.93, no.2, pp. 175-179

Thomas, M. and Morwitz, V. (2005). "Pennywise and Pound Foolish: The LeftDigit Effect in Price Cognition, Journal of Consumer Research, vol.32, pp. 54-64. 
Tversky, A. and Kahneman, D. (1986). "Rational Choice and the Framing of Decisions", The Journal of Business, vol.59, no.4, pp.S251-S278.

Wedel, M. and Leeflang, P.S.H. (1998) "A model for the effects of psychological pricing in Gabor-Granger price studies", Journal of Economic Psychology, vol.19, pp.237-260.

Yule, G. U. (1927). "On reading a scale", Journal of the Royal Statistical Society, vol.90, no.3, pp.570-587. 


\section{Appendix 1 - Derivation of Optimal Deposit and Mortgage Interest Rates}

\section{Section 1: Derivation of Optimal Deposit Interest Rates}

This section contains the calculations underlying two of the three cases observed in the model for deriving optimal deposit rates. These calculations display the optimal interest rate for these cases of rounding, and for rounding and truncation together for investors. The approach adopted here develops on similar lines to the calculations included in the text for case 1 of truncating naïve investors, and are included in this appendix for the sake of brevity.

\section{Case 2: Limited recall based on Rounding for Deposits}

To consider naïve investors who round interest rates first, consider the case where the bank is restricted to setting integer-valued deposit rates. Here, the profits from naïve and sophisticated investors will be equal, since deposit demand from the two groups will be the same. Now consider the general case in which the bank can set a non-integer deposit rate. For simplicity assume that naïve investors will round rates ending with 0.5 to the integer above. We can show that as long as $r_{d}$ is less than $\left[r_{d}^{s}\right]^{r}-0.5$, profits increase by increasing the rate to $\left[r_{d}^{s}\right]^{r}-0.5$; correspondingly, it can also be shown that if interest rates are above $\left[r_{d}^{s}\right]^{r}+0.5$, then profits increase by decreasing the interest rate to $\left[r_{d}{ }^{s}\right]^{r}+$ 0.5. Concavity ensures the first case for sophisticated investors. The result for the naïve investors is as follows. By going through two steps profits for investors can be shown to rise as any initial rate $r_{d}$ bringing interest rates down to $\left[r_{d}\right]^{r}-$ 0.5. Next, profits are further increased by moving from $\left[r_{d}\right]^{r}-0.5$ to $\left[r_{d}^{s}\right]^{r}-0.5$. Thus profits are maximised in the region $\left[\left[r_{d}^{s}\right]^{r}-0.5,\left[r_{d}^{s}\right]^{r}+0.5\right]$.

The above analysis assumes that all naïve investors may round up a rate ending 0.5. If some individuals need to be nearer to a whole number before rounding there may be a degree of clustering just above $\left[r_{d}{ }^{s}\right]^{r}-0.5$. We assume that a rate increment equal to the smallest interest rate increment recognised by the bank 
will cause investors to round upwards. This means that there may be a point of profit discontinuance at $\left[r_{d}^{s}\right]^{r}-0.5+\delta$ where $\delta$ is the smallest interest rate interval recognised by the bank. At points in the interior of the interval where the profit function is continuous, the maximum profit can be determined by calculus to be:

$$
r-r_{d}^{*}-c=-\left[\left(1-k_{R}\right) D\left(r_{d}^{*}\right)+k_{R} D\left(\left[r_{d}{ }^{s}\right]^{r}\right)\right] /\left(1-k_{R}\right) \partial D\left(r^{*}{ }_{d}\right) / \partial r^{*}{ }_{d}
$$

\section{Case 3: Limited recall based on Rounding and Truncation for Deposits}

To consider investors who use rounding and truncation together, first, consider the case where the bank is restricted to setting integer-valued deposit rates., the profits from naïve and sophisticated investors will be equal, since investment demand from the two groups will be the same. Now consider the general case in which the bank can set a non-integer deposit rate. To analyse the way in which the bank should set interest rates to maximise profits it is easiest to consider the three types of investor separately.

The general case, in which the bank can set a non-integer deposit rate, is considered two different effects, for naïve depositors who round and truncate separately. For truncation, as long as $r_{d}$ is less than $\left[r_{d}^{s}\right]_{-}^{t}$ profits from naïve truncating, depositors can be increased by raising interest rates to this level $\left[r_{d}^{s}\right]_{-}^{t}$. For the rounding case, as long as $r_{d}$ is less than $\left[r_{d}^{s}\right]^{r}-0.5$ profits from naïve rounding, depositors can be increased by raising interest rates to this level, $\left[r_{d}^{s}\right]^{r}-0.5$. These increases in the interest rate $r_{d}$ raise the profit banks can derive from both forms of naïve depositor. Correspondingly if $r_{d}$ is greater than $\left[r_{d}^{s}\right]_{+}^{t}$ profits can be increased by reducing interest rates to this level $\left[r_{d}{ }^{s}\right]_{+}^{t}$. Similarly, if $r_{d}$ is greater than $\left[r_{d}^{s}\right]^{r}+0.5$ profits can be increased by reducing interest rates to this level. From these observations we can indicate that bank profits are maximised when naïve truncating depositors are considered (following Kahn et al 1999) in the closed interval: $\left[\left[r_{d}^{s}\right]_{-}^{t},\left[r_{d}^{s}\right]_{+}^{t}\right]$, and profits are maximised for naïve rounding depositors in the closed interval: $\left[\left[r_{d}{ }^{s}\right]^{r}-0.5,\left[r_{d}{ }^{s}\right]^{r}+0.5\right]$. 
While the closed intervals for truncation and rounding will not generally coincide, if we take the smallest interval that includes both rounding and truncation intervals, bank profits from both types of naïve depositor is maximised in the closed interval:

$$
\left[\operatorname{MIN}\left(\left[r_{d}^{s}\right]_{-}^{t},\left(\left[r_{d}^{s}\right]^{r}-0.5\right)\right), \operatorname{MAX}\left(\left(\left[r_{d}^{s}\right]_{+}^{t}\right),\left[\left[r_{d}^{s}\right]^{r}+0.5\right)\right]\right.
$$

Lastly, by incorporating sophisticated depositors and assuming that $\left(r-r_{d}-c\right) D(r$, $\left.r_{d}, x\right)$ is a concave function of $r_{d}$, if $r_{d}$ is less than MIN $\left(\left[r_{d}^{s}\right]^{t},\left(\left[r_{d}^{s}\right]^{r}-0.5\right)\right)$, profits can be increased by raising the deposit interest rate to this level. Correspondingly if $r_{d}$ is greater than $\operatorname{MAX}\left(\left[r_{d}^{s}\right]_{+}^{t},\left(\left[r_{d}^{S}\right]^{r}+0.5\right)\right)$, profits can be increased by reducing the deposit interest rate to this level. Thus for all types of investors, profits are maximised in the closed interval:

$$
\left[\operatorname{MIN}\left(\left[r_{d}^{s}\right]_{-}^{t},\left(\left[r_{d}^{s}\right]^{r}-0.5\right)\right), \operatorname{MAX}\left(\left(\left[r_{d}^{s}\right]_{+}\right),\left[r_{d}^{s}\right]^{r}+0.5\right)\right]
$$

From this interval we can display that for different proportions of sophisticated, naïve rounding and naïve truncating depositors, profits are maximised at the end points of the closed interval or at one of three particular interior points in this closed interval. In addition to the points displayed in the diagram there may be a point of profit discontinuity at point $\left[r_{d}^{s}\right]^{r}-0.5+\delta$, reflecting individuals who will not round up at numbers ending exactly between two integers. The interval and two of the interior points are displayed in Diagram 1. If the optimal deposit rate is at a point in this interval where the profit function is continuous, calculus shows that a simple first order condition is satisfied:

$$
r-r_{d}{ }^{*}-c=\left[\left(1-k_{T}-k_{R}\right) D\left(r_{d}^{*}\right)+k_{T} D\left(\left[r_{d}^{*}\right]_{-}^{t}\right)+k_{R} D\left(\left[r_{d}^{*}\right]^{r}\right)\right] /\left(1-k_{T}-k_{R}\right) \partial D\left(r_{d}^{*}\right) / \partial r_{d}^{*}
$$


Diagram 1: Profit Maximising Intervals for Naïve Truncating, Naïve Rounding and Sophisticated Depositors

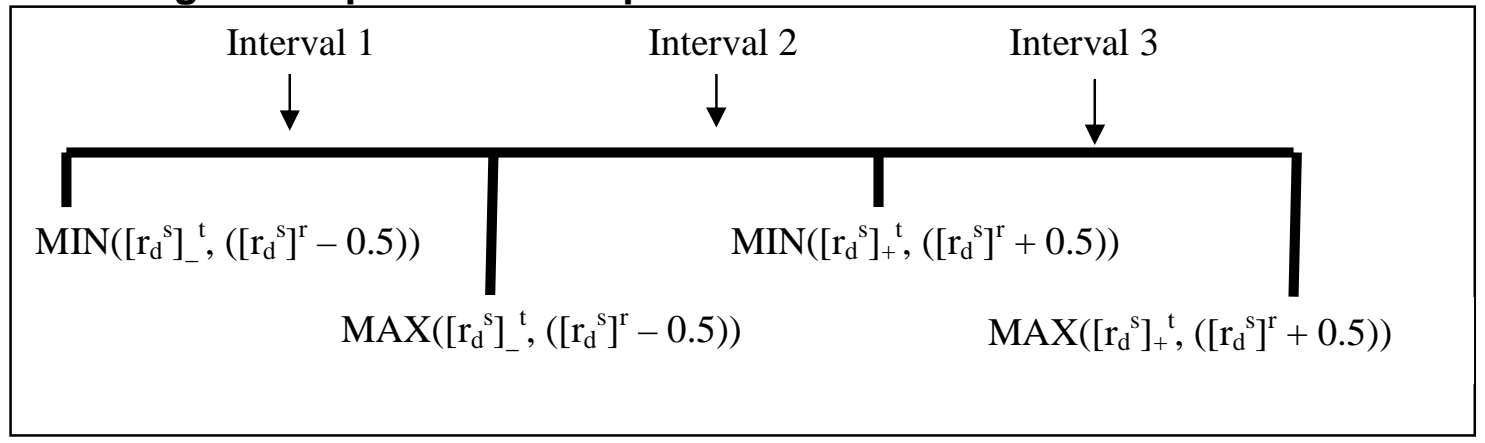

Section 2: The Derivation of Optimal Mortgage Interest Rates

This section contains the calculations underlying the three cases observed in the model for deriving optimal mortgage rates. These calculations display the optimal interest rate for these cases of rounding and truncation, both separately and together for borrowers. The analysis for borrowers is developed in a similar format to that considered for investors, where the sophisticated borrower will have a demand for mortgage borrowing which can be represented by:

$$
\mathrm{D}=\mathrm{D}\left(\mathrm{r}, \mathrm{r}_{\mathrm{m}}, \mathrm{x}\right)
$$

where $r_{m}$ is the bank's posted mortgage rate, $r$ is the market rate and $x$ is a vector of other variables which influence demand for mortgage lending. The demand of the naïve truncating borrower will depend on:

$$
D=D\left(r,\left[r_{m}\right]_{-}^{t}, x\right)
$$

and the demand of the naïve borrower who rounds interest rates will depend on:

$$
D=D\left(r,\left[r_{m}\right]^{r}, x\right)
$$

$k_{\mathrm{T}}$ is the proportion of borrowers who truncate interest rates, $\mathrm{k}_{\mathrm{R}}$ is the proportion of borrowers who round interest rates and $\left(1-k_{R}-k_{T}\right)$ is the proportion of borrowers who are sophisticated; $c$ represents non-interest expenses per $£$ of mortgages and $r$ represents the bank's wholesale funding rate (LIBOR). The bank's optimal profits may be presented as: 


$$
\left(r_{m}-r-c\right)\left[\left(1-k_{T}-k_{R}\right) D\left(r, r_{m}, x\right)+k_{T} D\left(r,\left[r_{m}\right]_{-}, x\right)+k_{R} D\left(r,\left[r_{m}\right]^{r}, x\right)\right]
$$

\section{Case 4: Limited recall based on Truncation for Mortgages}

Naïve borrowers who truncate to the integer component of a number will regard an interest rate change from $6.9 \%$ to $7.0 \%$ as a substantial increase from $6.0 \%$ to $7.0 \%$. We initially assume that all truncating borrowers truncate to the integer component of a number, although this model can be generalised to recognise different degrees of truncation. If a bank was faced only with naïve borrowers, to maximise profits, the bank would always set interest rates slightly below an integer to maximise the interest received without reducing demand for borrowing. To demonstrate this case, first, consider a bank is restricted to setting integervalued mortgage rates. In this case, the profits from naïve and sophisticated borrowers will be equal, since mortgage demand from the two groups will be the same. Furthermore because $\left(r_{m}-r-c\right) D\left(r, r_{m}, x\right)$ is a concave function in $r_{m}$, profits are also concave when interest rates are restricted to integer values, so that they are highest at either $\left[r_{m}^{s}\right]_{-}^{t}$ or $\left[r_{m}^{s}\right]^{t}+$

Now consider the general case in which the bank can set a non-integer mortgage rate. We can show that as long as $r_{m}$ is less than $\left[r_{m}^{s}\right]^{t}$, profits increase by increasing the rate to $\left[\mathrm{r}_{\mathrm{m}}^{\mathrm{s}}\right]^{\mathrm{t}}{ }_{-}$; correspondingly, it can also be shown that if interest rates are above $\left[\mathrm{rm}_{\mathrm{m}}{ }^{\mathrm{s}}\right]^{\mathrm{t}}{ }_{+}$, then profits increase by decreasing the interest rate to $\left[\mathrm{r}_{\mathrm{m}}{ }^{\mathrm{s}}{ }^{\mathrm{t}}{ }_{+}\right.$. To demonstrate the first of these claims, note that concavity ensures that since $\left[r_{m}{ }^{s}\right]^{t}$ - is less than $r_{m}{ }^{s}$, profits from the sophisticated borrowers increase by bringing the interest rate up to $\left[\mathrm{r}_{\mathrm{m}}{ }^{\mathrm{s}}\right]^{\mathrm{t}}$. The result for the naïve borrowers is as follows. From any initial rate $r_{m}$, increasing interest rates to $\left(\left[r_{m}\right]^{t}+\delta\right)$, where $\delta$ is the smallest possible interest rate increment, will boost the profits received from naïve borrowers. Further, increased profits can be achieved by moving from $\left(\left[\mathrm{r}_{\mathrm{m}}\right]^{\mathrm{t}}{ }_{+}-\delta\right)$ to $\left(\left[\mathrm{r}_{\mathrm{m}}{ }^{\mathrm{s}}\right]^{\mathrm{t}}-{ }_{-}\right)$, where profits are maximised in the region $\left[\left[r_{m}^{s}\right]_{-}^{t}-\delta,\left[r_{m}^{s}\right]^{t}{ }_{+}-\delta\right]$. In this region there are three possible cases: 


\section{Case 1}

$r_{m}=\left[r_{m}{ }^{s}\right]^{t}-\delta$

Profits are $\left(\left[r_{m}{ }^{s}{ }^{t}-\delta-r-c\right)\left[(1-k) D\left(r,\left[r_{m}{ }^{s}\right]^{t}-\delta, x\right)+k D\left(r,\left[r_{m}{ }^{s}\right]^{t}-\delta, x\right)\right]\right.$ (A9)

\section{Case 2}

$r_{m}=\left[r_{m}{ }^{s}\right]_{+}^{t}-\delta$

Profits are $\left(\left[r_{m}{ }^{s}\right]_{+}^{t}-\delta-r-c\right)\left[(1-k) D\left(r,\left[r_{m}{ }^{s}\right]_{+}^{t}-\delta, x\right)+k D\left(r,\left[r_{m}{ }^{s}\right]_{+}^{t}-\delta, x\right)\right]$

\section{Case 3}

$r_{m}$ is between $\left[r_{m}^{s}\right]^{t}$ and $\left[r_{m}{ }^{s}\right]_{+}^{t}-\delta$

(A11)

In this case the profit function is continuous so calculus is needed to display how profits are maximised. The proof analogous to Kahn et al (1999) Theorem 1 gives:

$$
r^{*}-r-c=-\left[\left(1-k_{T}\right) D\left(r_{m}^{*}\right)+k_{T} D\left(\left[r_{m}^{s}\right]^{t} \_\right)\right] /\left(1-k_{T}\right) \partial D\left(r_{m}^{*}\right) / \partial r_{m}^{*}
$$

\section{Case 5: Limited recall based on Rounding for Mortgages}

Discontinuities in the bank's profit function also arise from naïve rounding borrowers, who regard an interest rate change from, for example, $5.49 \%$ to $5.51 \%$, as a substantial increase from $5.0 \%$ to $6.0 \%$. If a bank was faced only with naïve rounding borrowers, rounding to the nearest integer, it maximises profits by setting interest rates just below the half way point between two integers, assuming naïve borrowers round up numbers ending exactly half way between two integers ${ }^{7}$. This position attracts the same demand from naïve borrowers, while providing increased interest payments to the bank.

\footnotetext{
${ }^{7}$ There is a potential complication in that it is not certain how naïve borrowers might round numbers ending exactly half way between integers (i.e. ending in 0.5). Some investors may not round up these numbers but instead round them down. In this event the bank may not wish to set an interest rate exactly half way between integers.
} 
To demonstrate this case, first consider the case where the bank is restricted to setting integer-valued mortgage rates. In this case, its profits from naïve and sophisticated borrowers will be equal, since mortgage demand from the two groups will be the same. Now consider the general case in which the bank can set a non-integer mortgage rate. We can show that as long as $r_{m}$ is less than $\left[r_{m}^{s}\right]^{r}-0.5$, profits rise by increasing the rate to $\left[r_{m}^{s}\right]^{r}-0.5$; correspondingly. It can also be shown that if interest rates are above $\left[r_{m}{ }^{s}\right]^{r}+0.5$, then profits increase by decreasing the interest rate to $\left[r_{m}^{s}\right]^{r}+0.5$. Concavity ensures the first case for sophisticated borrowers. The result for the naïve borrowers are as follows. By going through two steps, profits for naïve borrowers can be shown to rise. From any initial rate $r_{m}$, increasing interest rates to $\left[r_{m}\right]^{r}+0.5$ will boost profits from naïve borrowers. Next, increased profits can be achieved by moving from $\left[r_{m}\right]^{r}+$ 0.5 to $\left[r_{m}{ }^{s}\right]^{r}+0.5$, where profits are maximised in the region $\left[\left[r_{m}{ }^{s}\right]^{r}-0.5,\left[r_{m}{ }^{s}\right]^{r}+\right.$ $0.5]$.

The above analysis assumes that all naïve borrowers may round down at a rate ending 0.5. If some individuals need to be nearer to a whole number before rounding there may be a degree of clustering just below $\left[r_{d}^{s}\right]^{r}+0.5$. We assume that a rate decrement equal to the smallest interest rate decrement recognised by the bank will cause investors to round downwards. This means that there may be a point of profit discontinuance at $\left[r_{d}^{s}\right]^{r}+0.5-\delta$ where $\delta$ is the smallest interest rate interval recognised by the bank. At points in the interior of the interval where the profit function is continuous, the maximum profit can be determined by calculus to be:

$$
r^{*}-r-c=-\left[\left(1-k_{R}\right) D\left(r_{m}^{*}\right)+k_{R} D\left(\left[r_{m}^{*}\right]^{r}\right)\right] /\left(1-k_{R}\right) \partial D\left(r^{*}{ }_{m}\right) / \partial r_{m}^{*}
$$




\section{Case 6: Limited recall based on Rounding and Truncation for Mortgages}

To consider the case of the simultaneous use of rounding and truncating by borrowers, first, consider the case where the bank is restricted to setting integervalued mortgage rates. In this case, the profits from naïve and sophisticated borrowers will be equal, since demand from the two groups will be the same. Now consider the general case in which the bank can set a non-integer mortgage rate. To analyse the way in which the bank should set interest rates to maximise profits it is easiest to consider for the three types of borrower separately:

Naïve truncating borrowers: As shown in case 4, profits are maximised in the closed interval:

$$
\left[\left[r_{m}^{s}\right]_{-}^{t}-\delta,\left[r_{m}^{s}\right]_{+}^{t}-\delta\right]
$$

Naïve rounding borrowers: As shown in case 5, profits are maximised in the closed interval:

$$
\left[\left[r_{m}^{s}\right]^{r}-0.5,\left[r_{m}^{s}\right]^{r}+0.5\right]
$$

Generally the closed intervals for truncating and rounding borrowers will not coincide. If we take the smallest interval that includes both intervals we see that profits from both types of naïve borrowers are maximised in the closed interval:

$$
\left[\operatorname{MIN}\left(\left[r_{m}^{s}\right]^{t}-\delta,\left(\left[r_{m}^{s}\right]^{r}-0.5\right)\right), \operatorname{MAX}\left(\left[r_{m}^{s}\right]^{t}+\delta,\left[r_{m}^{s}\right]^{r}+0.5\right)\right]
$$

For sophisticated borrowers concavity ensures that if $r_{d}$ is less than $\operatorname{MIN}\left(\left[r_{m}{ }^{s}\right]_{-}\right.$$\delta$, $\left.\left(\left[r_{m}^{s}\right]^{r}-0.5\right)\right)$ profits can be increased by bringing the interest rate up to $\operatorname{MIN}\left(\left[r_{m}^{s}\right]_{-}-\delta\right.$, $\left.\left(\left[r_{m}{ }^{s}\right]^{r}-0.5\right)\right)$. If $r_{d}$ is greater than $\operatorname{MAX}\left(\left[r_{m}^{s}\right]_{+}-\delta\right.$, $\left.\left(\left[r_{m}^{s}\right]^{r}+0.5\right)\right)$ profits can be increased by bringing the interest rate down to $\operatorname{MAX}\left(\left[\mathrm{r}_{\mathrm{m}}{ }^{\mathrm{s}}\right]_{+}-\delta\right.$, $\left.\left(\left[r_{m}{ }^{s}\right]^{r}+0.5\right)\right)$. Thus for all types of borrowers, profits are maximised in the closed interval:

$$
\left[\operatorname{MIN}\left(\left[r_{m}^{s}\right]^{t}{ }_{-}-\delta,\left(\left[r_{m}^{s}\right]^{r}-0.5\right)\right), \operatorname{MAX}\left(\left[r_{m}^{s}\right]^{t}+-\delta,\left[r_{m}^{s}\right]^{r}+0.5\right)\right]
$$


From this interval we can display that for different proportions of sophisticated, naïve rounding and naïve truncating borrowers, profits are maximised at the end points of the closed interval or at one of three particular interior points in this closed interval. In addition to the points displayed in the diagram there may be a point of profit discontinuity at point $\left[r_{d}^{S}\right]^{r}+0.5-\delta$ reflecting individuals who will not round down at numbers ending exactly between two integers. The interval and two of the interior points are displayed in Diagram 2.

Now depending on the mix of types of investor, profit could be maximised at the end points of the interval, at one of two particular interior points in the interval:

$$
\operatorname{MAX}\left(\left[r_{m}{ }^{s}\right]^{t}-\delta,\left(\left[r_{m}^{s}\right]^{r}-0.5\right)\right) \text { and } \operatorname{MIN}\left(\left[r_{m}^{s}\right]^{t}{ }_{+}-\delta,\left[r_{m}^{s}\right]^{r}+0.5\right)
$$

or in the three intervals formed by the two end points and two interior points as displayed in Diagram 2. If the optimal borrowing rate is at a point in this interval where the profit function is continuous calculus shows that a simple first order condition is satisfied:

$$
\begin{aligned}
r_{m}{ }^{*}-r-c= & -\left[\left(1-k_{T}-k_{R}\right) D\left(r^{*}{ }_{m}\right)+k_{T} D\left(\left[r_{m}{ }^{*}\right]_{-}\right)+k_{R} D\left(\left[r_{m}{ }^{*}\right]^{r}\right)\right] \\
& /\left(1-k_{T}-k_{R}\right) \partial D\left(r^{*}{ }_{m}\right) / \partial r^{*}{ }_{m}
\end{aligned}
$$

Diagram 2: Profit Maximising Intervals for Naïve Truncating, Naïve Rounding and Sophisticated Borrowers

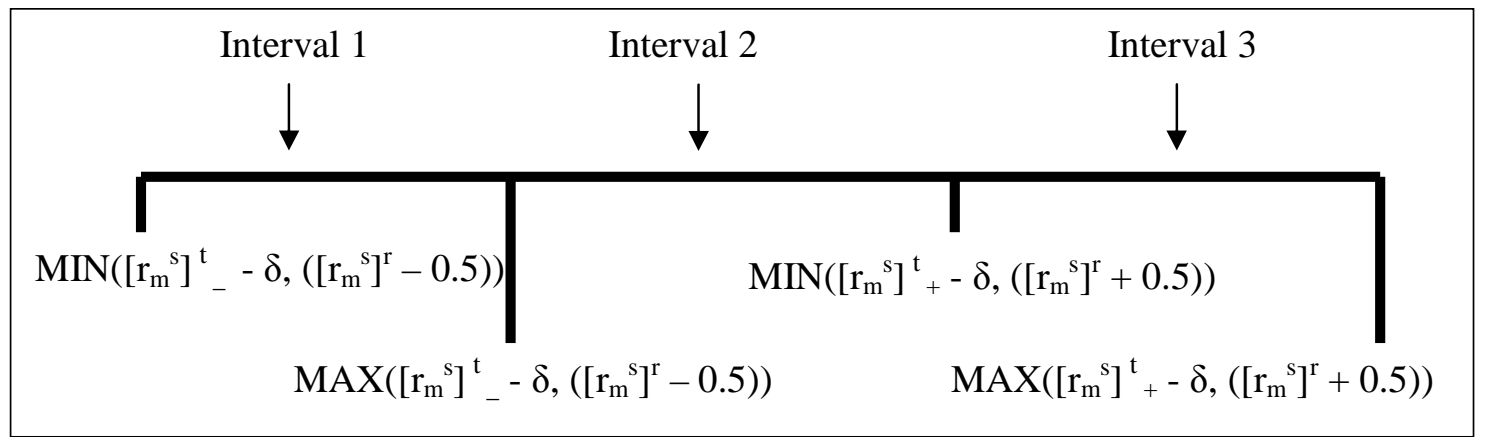




\section{Appendix 2}

\section{Panel 1: Naïve Truncating and Sophisticated Investors}

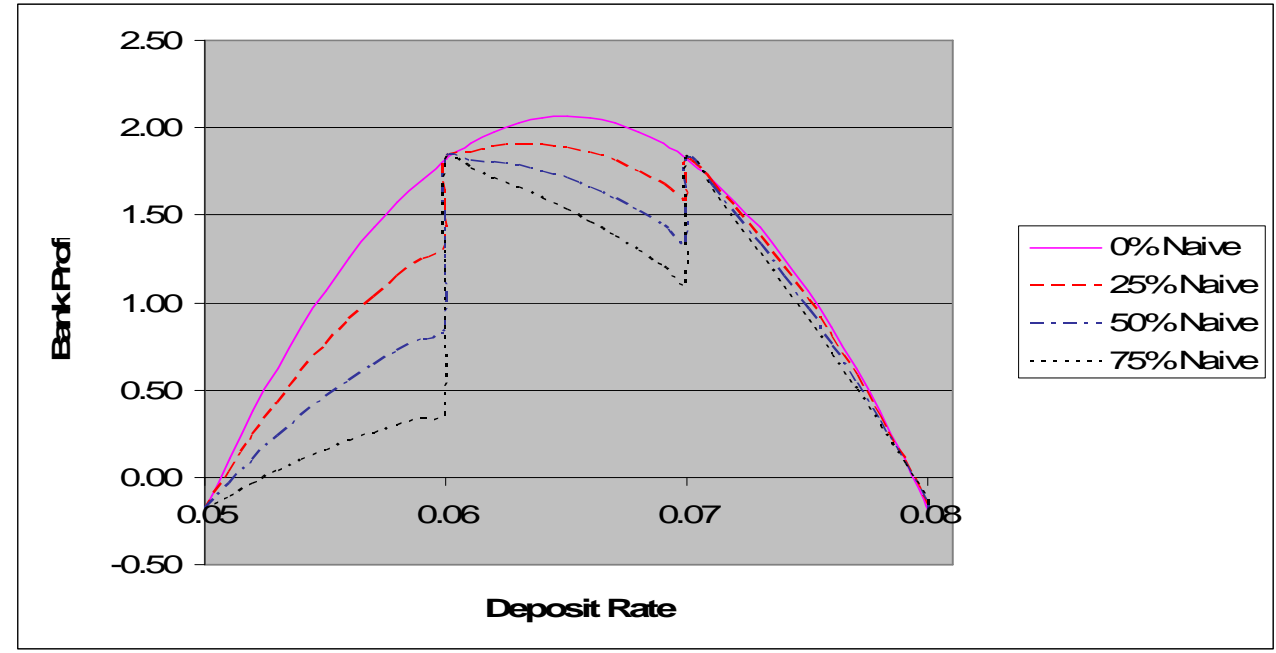

\section{Panel 2: Naïve Rounding and Sophisticated Investors}

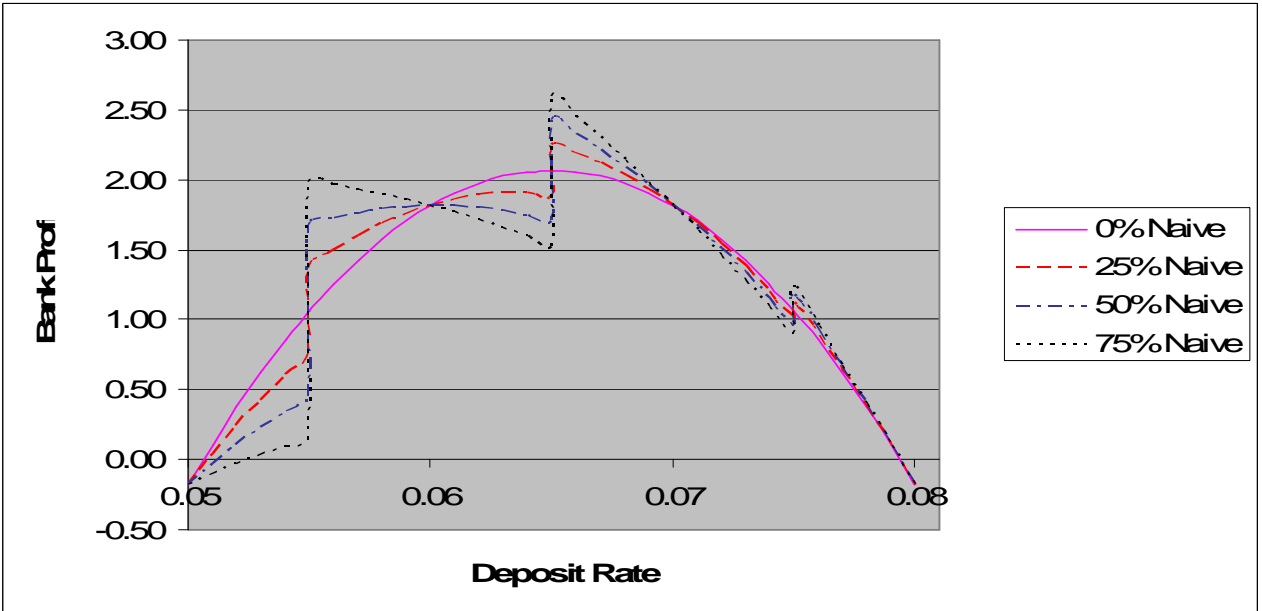

Panel 1 shows how bank profits will vary with the deposit interest rate for various combinations of naïve truncating and sophisticated investors. The parameters used in the calculations are $c=0.005$ and $D=a_{0}+a_{1} r+a_{2} r_{d}$, where $a_{0}=0$ and $a_{1} / a_{2}=-0.6$. The market interest rate is $r=8.4375 \%$. In the absence of naïve investors the profit maximising deposit rate is $6.5 \%$. Panel 2 shows how bank profits will vary with the deposit rate for various combinations of naïve rounding and sophisticated investors. In this diagram, for clarity, $\delta$ has been assumed to be 0 . 


\section{Panel 3: Naïve Truncating and Sophisticated Borrowers}

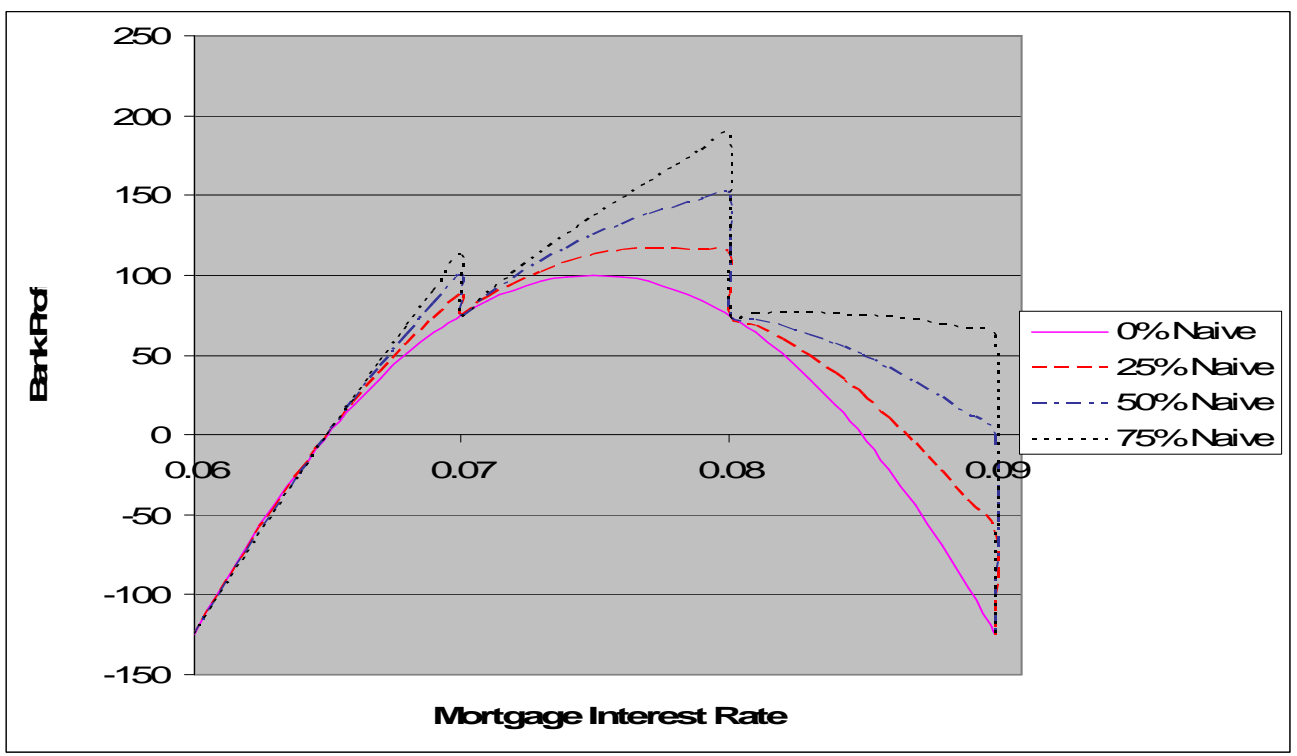

Panel 4: Naïve Rounding and Sophisticated Borrowers

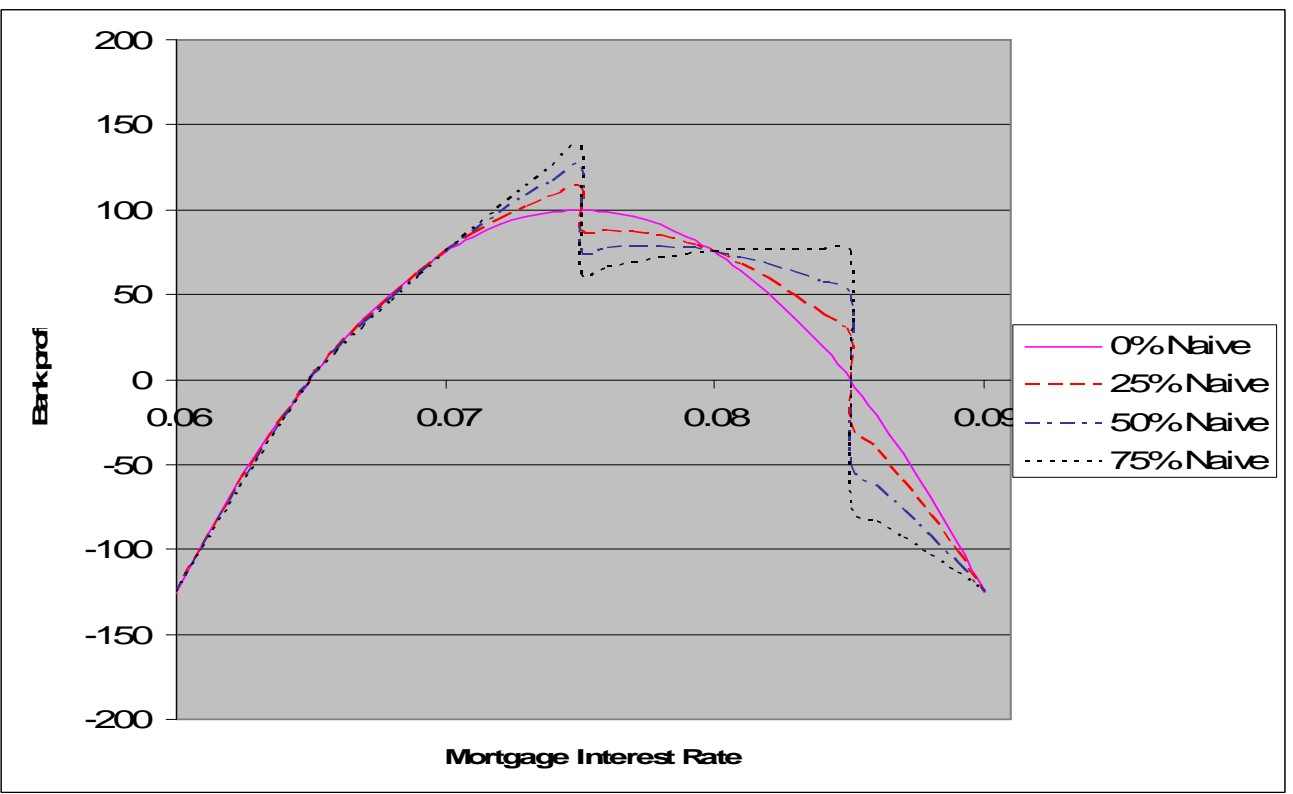

Panel 3 shows how bank profits will vary with the mortgage rate for various combinations of naïve truncating and sophisticated borrowers. The parameters used in the calculations are $c=0.005$ and $D=a_{0}+a_{1} r+a_{2} r_{d}$, where $a_{0}=0.049$ and $a_{1} / a_{2}=0.6$ and $a_{2}=-1$. The market interest rate is $r=6 \%$. We can observe the bank's profits as a function of the bank's deposit rate for the 4 different proportions of naïve borrowers. Overall, from both the model and Figure 3 the 
presence of naïve truncating borrowers will result in the clustering of bank mortgage rates just below integers. Panel 4 indicates that interest rate setting for mortgages in the presence of rounding borrowers, would result in clustering just below half points. 


\section{Appendix 3}

\section{Mantissa for Deposit Rates}

\begin{tabular}{|c|c|c|c|c|c|c|c|c|}
\hline Mantissa & Frequency & $\begin{array}{l}\text { Percentage } \\
\text { Frequency }\end{array}$ & Mantissa & Frequency & $\begin{array}{l}\text { Percentage } \\
\text { Frequency }\end{array}$ & Mantissa & Frequency & $\begin{array}{l}\text { Percentage } \\
\text { Frequency }\end{array}$ \\
\hline 51 & 28 & 0.05 & 85 & 1947 & 3.16 & 19 & 24 & 0.04 \\
\hline 52 & 21 & 0.03 & 86 & 13 & 0.02 & 20 & 2013 & 3.26 \\
\hline 53 & 28 & 0.05 & 87 & 68 & 0.11 & 21 & 58 & 0.09 \\
\hline 54 & 82 & 0.13 & 88 & 161 & 0.26 & 22 & 36 & 0.06 \\
\hline 55 & 1311 & 2.13 & 89 & 38 & 0.06 & 23 & 37 & 0.06 \\
\hline 56 & 108 & 0.18 & 90 & 1779 & 2.89 & 24 & 62 & 0.1 \\
\hline 57 & 7 & 0.01 & 91 & 33 & 0.05 & 25 & 5449 & 8.84 \\
\hline 58 & 5 & 0.01 & 92 & 28 & 0.05 & 26 & 41 & 0.07 \\
\hline 59 & 55 & 0.09 & 93 & 15 & 0.02 & 27 & 31 & 0.05 \\
\hline 60 & 2365 & 3.84 & 94 & 44 & 0.07 & 28 & 15 & 0.02 \\
\hline 61 & 22 & 0.04 & 95 & 1238 & 2.01 & 29 & 79 & 0.13 \\
\hline 62 & 17 & 0.03 & 96 & 84 & 0.14 & 30 & 1946 & 3.16 \\
\hline 63 & 201 & 0.33 & 97 & 7 & 0.01 & 31 & 76 & 0.12 \\
\hline 64 & 102 & 0.17 & 98 & 18 & 0.03 & 32 & 9 & 0.01 \\
\hline 65 & 1809 & 2.93 & 99 & 35 & 0.06 & 33 & 39 & 0.06 \\
\hline 66 & 32 & 0.05 & 0 & 10879 & 17.64 & 34 & 36 & 0.06 \\
\hline 67 & 29 & 0.05 & 1 & 33 & 0.05 & 35 & 1915 & 3.11 \\
\hline 68 & 48 & 0.08 & 2 & 43 & 0.07 & 36 & 27 & 0.04 \\
\hline 69 & 58 & 0.09 & 3 & 13 & 0.02 & 37 & 29 & 0.05 \\
\hline 70 & 1801 & 2.92 & 4 & 57 & 0.09 & 38 & 155 & 0.25 \\
\hline 71 & 4 & 0.01 & 5 & 1575 & 2.55 & 39 & 24 & 0.04 \\
\hline 72 & 59 & 0.1 & 6 & 73 & 0.12 & 40 & 2264 & 3.67 \\
\hline 73 & 11 & 0.02 & 7 & 32 & 0.05 & 41 & 44 & 0.07 \\
\hline 74 & 23 & 0.04 & 8 & 27 & 0.04 & 42 & 1 & 0 \\
\hline 75 & 5346 & 8.67 & 9 & 28 & 0.05 & 43 & 75 & 0.12 \\
\hline 76 & 60 & 0.1 & 10 & 2239 & 3.63 & 44 & 55 & 0.09 \\
\hline 77 & 18 & 0.03 & 11 & 38 & 0.06 & 45 & 1570 & 2.55 \\
\hline 78 & 30 & 0.05 & 12 & 34 & 0.06 & 46 & 32 & 0.05 \\
\hline 79 & 29 & 0.05 & 13 & 192 & 0.31 & 47 & 33 & 0.05 \\
\hline 80 & 1833 & 2.97 & 14 & 6 & 0.01 & 48 & 29 & 0.05 \\
\hline 81 & 44 & 0.07 & 15 & 2110 & 3.42 & 49 & 16 & 0.03 \\
\hline 82 & 21 & 0.03 & 16 & 33 & 0.05 & 50 & 6726 & 10.91 \\
\hline 83 & 33 & 0.05 & 17 & 47 & 0.08 & & & \\
\hline 84 & 61 & 0.1 & 18 & 47 & 0.08 & Total & 22946 & 100 \\
\hline
\end{tabular}


Mantissa for Mortgage Rates

\begin{tabular}{|c|c|c|c|c|c|c|c|c|}
\hline Mantissa & Frequency & $\begin{array}{l}\text { Percentage } \\
\text { Frequency }\end{array}$ & Mantissa & Frequency & $\begin{array}{l}\text { Percentage } \\
\text { Frequency }\end{array}$ & Mantissa & Frequency & $\begin{array}{l}\text { Percentage } \\
\text { Frequency }\end{array}$ \\
\hline 51 & 0 & 0 & 85 & 440 & 2.85 & 19 & 99 & 0.64 \\
\hline 52 & 0 & 0 & 86 & 1 & 0.01 & 20 & 301 & 1.95 \\
\hline 53 & 15 & 0.1 & 87 & 9 & 0.06 & 21 & 16 & 0.1 \\
\hline 54 & 183 & 1.18 & 88 & 15 & 0.1 & 22 & 8 & 0.05 \\
\hline 55 & 221 & 1.43 & 89 & 271 & 1.75 & 23 & 19 & 0.12 \\
\hline 56 & 9 & 0.06 & 90 & 176 & 1.14 & 24 & 491 & 3.18 \\
\hline 57 & 0 & 0 & 91 & 0 & 0 & 25 & 562 & 3.63 \\
\hline 58 & 2 & 0.01 & 92 & 0 & 0 & 26 & 0 & 0 \\
\hline 59 & 367 & 2.37 & 93 & 19 & 0.12 & 27 & 0 & 0 \\
\hline 60 & 330 & 2.13 & 94 & 137 & 0.89 & 28 & 9 & 0.06 \\
\hline 61 & 0 & 0 & 95 & 913 & 5.9 & 29 & 168 & 1.09 \\
\hline 62 & 0 & 0 & 96 & 17 & 0.11 & 30 & 85 & 0.55 \\
\hline 63 & 0 & 0 & 97 & 3 & 0.02 & 31 & 5 & 0.03 \\
\hline 64 & 437 & 2.83 & 98 & 48 & 0.31 & 32 & 4 & 0.03 \\
\hline 65 & 241 & 1.56 & 99 & 1792 & 11.59 & 33 & 0 & 0 \\
\hline 66 & 3 & 0.02 & 0 & 315 & 2.04 & 34 & 114 & 0.74 \\
\hline 67 & 0 & 0 & 1 & 0 & 0 & 35 & 372 & 2.41 \\
\hline 68 & 13 & 0.08 & 2 & 0 & 0 & 36 & 0 & 0 \\
\hline 69 & 429 & 2.77 & 3 & 5 & 0.03 & 37 & 0 & 0 \\
\hline 70 & 615 & 3.98 & 4 & 57 & 0.37 & 38 & 1 & 0.01 \\
\hline 71 & 9 & 0.06 & 5 & 125 & 0.81 & 39 & 172 & 1.11 \\
\hline 72 & 1 & 0.01 & 6 & 0 & 0 & 40 & 173 & 1.12 \\
\hline 73 & 49 & 0.32 & 7 & 1 & 0.01 & 41 & 0 & 0 \\
\hline 74 & 1196 & 7.73 & 8 & 0 & 0 & 42 & 6 & 0.04 \\
\hline 75 & 679 & 4.39 & 9 & 143 & 0.92 & 43 & 30 & 0.19 \\
\hline 76 & 7 & 0.05 & 10 & 343 & 2.22 & 44 & 282 & 1.82 \\
\hline 77 & 0 & 0 & 11 & 2 & 0.01 & 45 & 601 & 3.89 \\
\hline 78 & 16 & 0.1 & 12 & 0 & 0 & 46 & 6 & 0.04 \\
\hline 79 & 229 & 1.48 & 13 & 4 & 0.03 & 47 & 15 & 0.1 \\
\hline 80 & 220 & 1.42 & 14 & 176 & 1.14 & 48 & 33 & 0.21 \\
\hline 81 & 0 & 0 & 15 & 131 & 0.85 & 49 & 779 & 5.04 \\
\hline 82 & 8 & 0.05 & 16 & 5 & 0.03 & 50 & 486 & 3.14 \\
\hline 83 & 6 & 0.04 & 17 & 3 & 0.02 & & & \\
\hline 84 & 158 & 1.02 & 18 & 33 & 0.21 & Totals & 15464 & 100 \\
\hline
\end{tabular}

